\title{
Integrating numerical cognition research and mathematics education to strengthen the teaching and learning of early number
}

\author{
Zachary Hawes*I,2 (D), Rebecca Merkley $^{3}$ (D), Christine L. Stager ${ }^{4}$ and \\ Daniel Ansari ' \\ 'Department of Psychology, Brain and Mind Institute, University of Western Ontario, \\ London, Ontario, Canada \\ ${ }^{2}$ Applied Psychology \& Human Development, Ontario Institute for Studies in \\ Education, University of Toronto, Toronto, Ontario, Canada \\ ${ }^{3}$ Institute of Cognitive Science, Carleton University, Ottawa, Ontario, Canada \\ ${ }^{4}$ Thames Valley District School Board, London, Ontario, Canada
}

Background. Research into numerical cognition has contributed to a large body of knowledge on how children learn and perform mathematics. This knowledge has the potential to inform mathematics education. Unfortunately, numerical cognition research and mathematics education remain disconnected from one another, lacking the proper infrastructure to allow for productive and meaningful exchange between disciplines. The present study was designed to address this gap.

Aim. This study reports on the design, implementation, and effects of a 16-week (25hour) mathematics Professional Development (PD) model for Kindergarten to Grade 3 educators and their students. A central goal of the PD was to better integrate numerical cognition research and mathematics education.

Sample. A total of $45 \mathrm{~K}-3$ educators and I 80 of their students participated.

Methods. To test the reproducibility and replicability of the model, the study was carried out across two different sites, over a two-year period, and involved a combination of two different study designs: a quasi-experimental pre-post-research design and a within-group crossover intervention design.

Result. The results of the first implementation (Year I), indicated that compared to a control group, both teachers and students benefited from the intervention. Teachers demonstrated gains on both a self-report measure and a test of numerical cognition knowledge, while students demonstrated gains in number line estimation, arithmetic, and numeration. In Year 2, teachers in the intervention group demonstrated greater improvements than the control group on the self-report measure, but not the test of numerical cognition knowledge. At the student level, there was some evidence of gains in numeration.

Conclusion. The current PD model is a promising approach to better integrate research and practice. However, more research is needed to determine in which school contexts the model is most effective.

\footnotetext{
*Correspondence should be addressed to Zachary Hawes, Dr. Eric Jackman Institute of Child Study, Applied Psychology \& Human Development, University of Toronto, 45 Walmer Road, Toronto, Ontario, Canada M5R 2X2 (email: zack.hawes@utoronto.ca).
} 
I say moreover that you make a great, a very great mistake, if you think psychology, being the science of the mind's laws, is something from which you can deduce definite programmes and schemes and methods of instruction for immediate schoolroom use. Psychology is a science, and teaching, is an art; and sciences never generate arts directly out of themselves. An intermediary inventive mind must make the application, by using its originality (William James, 1899, p. 23).

\section{Background}

The above quote points to a central problem facing both educators and psychologists alike: How to apply the science of learning to the classroom. As this quote also reminds us, the implications for classroom instruction do not immediately follow from the science of learning. Instead, intermediary actions are needed to most optimally merge the science of learning and the practice of teaching. The present study is a response to this call for action.

We address the question of whether and to what extent both teachers and their students benefit from a model of teacher professional development (PD) explicitly aimed to better integrate research in numerical cognition with mathematics instruction. More specifically, we report on the design, implementation, and effects of an in-service mathematics PD model for teachers of kindergarten-3rd Grade. The PD model centres around the translation and application of key findings from the field of numerical cognition - a branch of cognitive science that involves the interdisciplinary study of the cognitive, developmental, and neural bases of numerical and mathematical thought. Throughout the PD model (25 hr over a 3-month period), numerical cognition research serves as both a base and point of return to better understand children's numerical thinking. Indeed, central to our model is the hypothesis that by better understanding children's numerical thinking, teachers may be better equipped to assess student learning and to plan and deliver mathematics instruction.

\section{Foundations on which the current teacher PD model was built}

If research-to-practice gaps are the problem, what are some potential solutions? In this section, we briefly review three bodies of work that have each achieved some levels of success in better integrating research and practice. These research programmes were instrumental in forming the theoretical underpinnings and design of the current intervention.

One approach to narrowing the research-to-practice gap is a methodological approach known as design research (Brown, 1992; Collins, 1992). Design research involves an iterative cycle of intervention design, implementation, and evaluation in real-world learning environments (e.g., classrooms). Importantly, this occurs in partnership with the various stakeholders involved (e.g., teachers). Design research was borne in response to the difficulties of taking laboratory-based learning interventions and implementing them in classroom and school contexts (Brown, 1992). These difficulties include the emergent properties of real-world learning environments (classrooms) that are the products of multifaceted and largely uncontrollable variables (e.g., social dynamics of individual students across different classrooms). As the name suggests, design research has its basis in the scientifically informed 'trial and error' approaches of the design sciences, including engineering, artificial intelligence, and aeronautics (Collins, Joseph, \& Bielaczyc, 2004; Nathan \& Sawyer, 2014; Simon, 1969). This approach can be likened to beta testing. A 
product is first designed and then released to actual users who then provide feedback, report bugs, etc. This feedback is then used to create a more optimally functioning and user-informed product. Educational design research functions similarly. With design research, learning interventions are not viewed as static, prescriptive 'how-to-teach $\mathrm{x}$ ' recipes but are implemented with built-in feedback mechanisms. For example, teachers might be encouraged to adapt the intervention where they see fit based on the feedback they receive from their students. In the present intervention, we borrowed this particular feature of design research. In designing our intervention, we built certain degrees of freedom into the intervention model - specifying beforehand where and what aspects of the intervention we would allow and want to vary. Specifically, we aimed to utilize teacher expertise in the delivery of the student intervention activities. Teachers were encouraged to take the activities (designed and presented to the group by the research team) and adapt them where they saw need for revision. In line with design research, we did this in an effort to (1) build teacher agency and incorporate professional feedback into the model and (2) to gradually refine and ultimately build better student intervention activities (e.g., Moss, Bruce, Caswell, Flynn, \& Hawes, 2016).

Another approach to narrowing the research-practice gap is a form of teacher PD known as Cognitively Guided Instruction (CGI; Carpenter, Fennema, Franke, Levi, \& Empson, 2014; Carpenter, Fennema, Peterson, Chiang, \& Loef, 1989). At its core, CGI is an approach to working with teachers that involves sharing research on children's mathematical thinking and then using this knowledge as a basis for assessment and instruction (Carpenter et al., 1989; Franke, Carpenter, Levi, \& Fennema, 2001). For example, as described in various iterations of this model, teachers are introduced to research-based frameworks for understanding children's arithmetic development and strategy use (e.g., identifying different problem types and the mental actions associated with each problem type). This knowledge is then more readily accessible and utilized by teachers during their assessment and instruction of children's arithmetic (Carpenter et al., 1989). Various iterations of the CGI model have demonstrated the critical link between a teacher's knowledge of children's numerical thinking and their approach to classroom instruction. Indeed, educators' knowledge of children's numerical thinking has been shown to be a powerful driver of instructional change, associated with improvements in children's numerical reasoning, and self-reported understanding and confidence in problem-solving abilities (e.g., see Carpenter et al., 1989, 2014; Franke, Carpenter, Fennema, Ansell, \& Behrend, 1998).

It is worth considering the mechanisms that underlie this link. In other words, why and how does exposing educators to research on children's numerical thinking serve as a catalyst for instructional change, including improved student learning? As alluded to above, research into children's mathematical thinking has the potential to change what educators' attend and respond to in practice. For example, research into how students' think about and interpret the equal sign $(=)$ has revealed robust and consistent student misconceptions (e.g., Baroody \& Ginsburg, 1983; Falkner, Levi, \& Carpenter, 1999; Matthews \& Fuchs, 2020; McNeil \& Alibali, 2005). Rather than interpreting the equal sign as relational and as a symbol meaning 'the same as' or 'equivalent to', the majority of students view the equal sign as an operator and as a symbol meaning 'to do something' or 'to add up the numbers'. As a result, when confronted with a question, such as, $8+4=\ldots+5$, most elementary school students incorrectly write 12 or 17 on the blank line (e.g., Falkner et al., 1999). Unfortunately, educators are not always aware of this misconception (e.g., see Asquith, Stephens, Knuth, \& Alibali, 2007; Falkner et al., 1999). Without such awareness, there is little reason to expect classroom practice to develop 
students' understanding of mathematical equivalence. In turn, children may be at risk of incomplete understandings of other aspects of mathematics, namely algebra - a wellknown gatekeeper within mathematics, preventing many children from further advancing in mathematics (Byrd, McNeil, Chesney, \& Matthews, 2015; Matthews \& Fuchs, 2020). Fortunately, there is strong evidence that children's understanding of the equal sign can be improved through an assortment of interventions (McNeil, Fyfe, \& Dunwiddie, 2015; McNeil, Hornburg, Brletic-Shipley, \& Matthews, 2019; Powell et al., 2020); many of which are relatively easy to implement in practice, including presenting arithmetic problems in non-standard formats (e.g., $\ldots=4+3$; McNeil et al., 2015). This example highlights the important link between a teacher's knowledge of children's numerical thinking, their approach to practice, and the effects this has on student learning.

To summarize, the CGI model places children's thinking at it centre, adhering to the belief that stronger and more nuanced understanding of children's mathematical thinking provides educators with a more organized and structured 'mental model' of the learner(s) (Carpenter et al., 1989; Willingham, 2017). That is, through sharing and discussing research on children's mathematical thinking, as well as opportunities to apply research to practice, educators gain an improved reference for what to look for in terms of student thinking and the implications this has for subsequent instruction. While our approach to teacher PD differs from CGI in some important ways (expanded on below), it shares the hypothesis that research into children's numerical thinking has the potential to change how educators approach their practice, and in turn, influence their students' learning.

Lastly, the current intervention builds on a model of teacher PD known as the Math for Young Children Project (Hawes, Moss, Caswell, Naqvi, \& MacKinnon, 2017; Moss et al., 2016). Inspired by Japanese Lesson Study and design research approaches to teacher PD, the Math for Young Children model provides an infrastructure that promotes collaborative inquiry and communication between teachers and researchers (Moss, Hawes, Naqvi, \& Caswell, 2015). Like Japanese Lesson Study, teachers and researchers undergo an in-depth study of a particular domain of mathematics (e.g., spatial reasoning). Drawing on both published research and teachers' own experiences and in-class observations, the team seeks to better understand both their own and their students' thinking and understanding in a particular domain of mathematics. Similar to CGI, children's mathematical thinking lies at the centre of the model. By better understanding children's thinking, it is theorized that educators are better prepared to plan, deliver, and assess mathematics instruction and learning. In turn, these activities serve to further elucidate children's thinking, contributing to an improved mental model of the learner(s) and the conditions believed to strengthen the learning of mathematics.

While various iterations of this approach exist (e.g., see Bruce, Flynn, \& Bennett, 2016; Moss et al., 2015), the present study is most closely related to the model described in Hawes et al. (2017). The authors describe the design, implementation, and effects of a 32week version of the model, focused on the integration of research and practice related to children's spatial thinking. Teachers and researchers met regularly to share and discuss research, classroom observations, and approaches to assessing and improving young children's (kindergarten-Grade 2) spatial thinking. The present study follows this same approach, but focuses on the integration of research and practice as it relates to children's numerical thinking. Like the present study, teachers were provided with a series of intervention activities to implement in their classrooms between meetings. During each whole-group meeting, time was set aside for each educator to share and discuss their experiences with implementation (e.g., successes, failures, wonderings, and extensions). Critically, teachers were encouraged to take the activities and 'make them their own', 
adapting and revising the activities based on their own professional judgement and assessment of their own students' learning needs. Compared to a control group, children in the intervention classrooms demonstrated widespread gains on assessments of spatial and geometric thinking, as well as some evidence of far transfer to a measure of numerical reasoning. Other iterations of this approach to teacher PD and the associated classroombased intervention have been linked to quantitative gains in children's geometric and spatial reasoning, as well as qualitative evidence of change in teachers' content knowledge and self-confidence (see Hawes et al., 2017; Moss et al., 2015).

The present study builds on the design and approach to PD described by Hawes et al. (2017), but aims to extend it in some key ways. First, in the current study, we focus the PD on improving key facets of children's numerical reasoning (e.g., cardinality, composition/ decomposition of number, place value, proportional reasoning). Given the widely recognized importance of young children's numerical reasoning for later mathematical and academic success (e.g., Duncan et al., 2007), it is crucial to target this area of instruction in the early years. Second, our model places much more emphasis on the integration of cognitive science and mathematics instruction. More specifically, we focus additional time and effort sharing and discussing relations between cognitive processes and strategies and their relations to mathematical learning and performance. Additionally, in accordance with the emerging disciplines of Mind, Brain, and Education (aka Educational Neuroscience), we share and discuss with teachers some of the recent insights from cognitive developmental neuroscience hypothesized to be relevant to the improvement of classroom instruction (e.g., brain plasticity, neuromyths, brain-related responses during arithmetic; see Dubinsky, Roehrig, \& Varma, 2013). Lastly, empirical studies of the model have been limited to measuring the effects of the intervention at the student level. This study is the first to measure the effectiveness of the model at both the student and teacher levels. Specifically, we examine the extent to which the intervention influences teachers' content knowledge, self-perceived content knowledge, and math anxiety/comfort level.

\section{The present study}

The purpose of this study was to address the research-to-practice gap in the teaching and learning of early number. Building on the teacher PD models described above, we designed a 25-hr in-service PD intervention that aimed to better integrate research in numerical cognition with the instruction of early years mathematics. Borrowing from these different approaches, our model incorporates features of design research (i.e., builtin teacher feedback mechanisms) and uses research on children's numerical thinking as the basis for facilitating both teacher change and student change. We predicted that our model of teacher PD would be an effective means for increasing both teacher learning and student learning. More specifically, we predicted that our intervention would lead to gains in teachers' awareness and knowledge of numerical cognition research and work towards alleviating teacher math anxiety. It was through engaging teachers in research and its application to classroom learning that we also expected to see evidence of increased student learning. Given that the teacher PD was aimed at the translation and application of key topics within the numerical cognition literature (e.g., research related to cardinality, ordinality, number lines, and arithmetic strategies), we predicted that these would be the aspects of children's mathematical thinking where the largest gains would occur. 


\section{Methods}

\section{Study design and procedure}

This study occurred over two consecutive school years (2016/2017 and 2017/2018) and involved a combination of two different study designs: a quasi-experimental pre-postresearch design and a within-group crossover intervention design. The crossover design was possible because the control school in the first year of the study (Year 1) participated as the intervention group in the second year of the study (Year 2). In total, three public elementary schools participated across the 2-year study. Schools were selected in consultation with the district school board and the explicit need to work with schools well-matched in sociodemographic characteristics and mathematics performance. All three schools were selected from the same predominantly White, low-income neighbourhood in London, Ontario, Canada and consistently perform well below the provincial average in mathematics. The school board identified these schools as those with the highest need for mathematics intervention (consistently performing in the bottom 10th percentile of schools in a board of 154 elementary schools). All three schools based their mathematics programming on the curriculum expectations outlined by the Ontario Ministry of Education (https://www.dcp.edu.gov.on.ca/en/curriculum\#elementary).

In the first year of the study, two of the three schools were randomly assigned to either the experimental or the 'waitlist' control condition (see Figure 1). Prior to data collection, the school principal and kindergarten-Grade 2 teachers gave their consent to participate. Information letters and consent forms were then sent home by the participating classroom teachers to the parents of children in their classrooms. Children whose parent/guardian provided consent for them to participate were randomly selected to

\section{(a) INTERVENTION CONDITION}

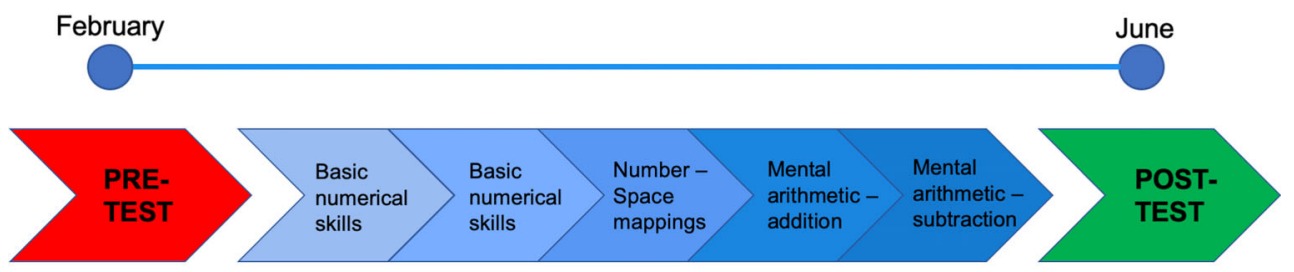

5 days of teacher PD focused on children's numerical reasoning

(b) CONTROL CONDITION

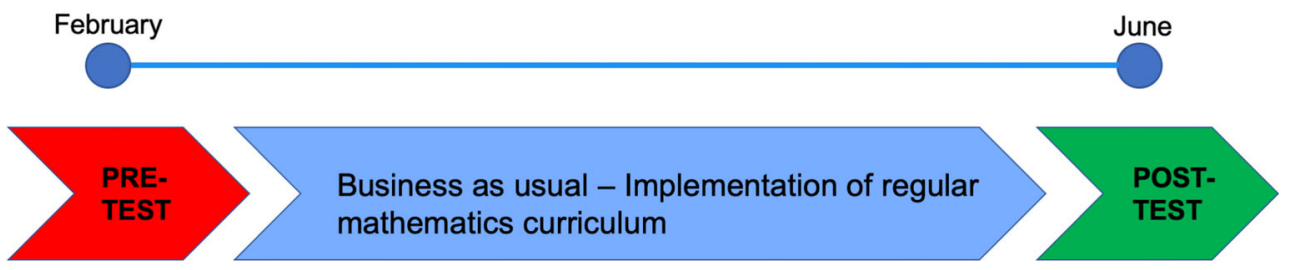

Figure I. A schematic of the research design/time frame and structure of the teacher professional development intervention. Each blue chevron in Figure A corresponds to the content focus for each day of the PD. 
participate in the pre- and post-tests. We were not able to test all children for whom we had consent due to time and resource limitations.

In the second year of the study, the control group from the previous year participated as the experimental group. In that same year, the third school, introduced above, participated as a control group. The same teacher, principal, and parent/child consent procedure described above was employed. Likewise, children whose parent/guardian provided consent for them to participate were randomly selected to participate in the preand post-testing assessments. The study design and procedure were approved by the University of Western Ontario's Non-medical Research Ethics Board (NMREB) and the participating school board's ethics committee.

In both years of the study, the intervention occurred over the same 3-month period (1st week of March to 1st week of June). Within this time frame, teachers received 5 full days (9 am-3:30 pm) of paid teacher release to participate in the intervention. Each of the 5 days was spaced out approximately 3-4 weeks from one another. Each day of the intervention followed the same general structure, but varied in the specific content addressed (see Figure 1). In total, the in-school teacher intervention was approximately $25 \mathrm{hr}$ in duration. All pre- and post-testing also occurred during the same time frame in each year of the study. Moreover, because some children $(n=48)$ participated in both the control and experimental conditions (in different years), we tested these children at near identical pre- and post-dates across both years. This allowed us to accurately compare within-participant growth across both conditions (experimental vs. control).

\section{Participants}

Year I

Teacher participants. In the first year of the study, 24 educators participated (intervention group $=15$; control group $=9$ ). The two groups were well-matched in terms of years of teaching experiences (mean intervention group $=10.57$ years, $S D=5.88$; mean control group $=11.00$ years, $S D=8.43$ ). Note that one teacher in the intervention group did not provide years of teaching experience. Teachers in both groups completed identical pre- and post-test measures prior to and immediately following the 3-month intervention period.

Child participants. A total of 107 children participated $\left(M_{\text {age }}=5.95\right.$ years, $S D=1.37$; females $=58$; males $=49$ ) in the pre-post-testing. Fifty-two children were randomly selected for pre-post-testing from the intervention classrooms $\left(M_{\mathrm{age}}=6.09, S D=1.17\right.$; females $=27$; males $=25$ ), and fifty-five were randomly selected from the control classrooms $\left(M_{\text {age }}=5.81, S D=1.22\right.$; females $=31 ;$ males $\left.=24\right)$. Note that random selection was done for each grade level in an effort to balance the number of children from each grade across both conditions. Pre- and post-testing took part during a 2-week period before and immediately following the intervention.

Year 2

Teacher participants. A total of 27 educators participated in Year 2 (intervention group $=15$; control group $=12$ ). The two groups were well-matched in terms of years of teaching experiences (mean intervention group $=11.83$ years, $S D=8.68$; mean control 
group $=10.92$ years, $S D=6.35$ ). Teachers in both groups completed identical pre- and post-test measures prior to and immediately following the 3-month intervention period.

Child participants. A total of 121 children participated $\left(M_{\text {age }}=6.72\right.$ years, $S D=1.42$; females $=66$; males $=55$ ) in the pre-post-testing. The intervention group consisted primarily of children who had participated as control participants in the previous year $(n=48)$. That is, 48 students from the Year 1 control group were available to take part in the intervention group 1 year later (Year 2). In order to increase the sample size and better match the intervention group with the Year 2 control group, an additional nine children were selected to participate. In total, 57 children were randomly selected to participate in the intervention group $\left(M_{\text {age }}=6.57\right.$ years, $S D=1.36$; females $=32$; males $\left.=25\right)$. Sixtyfour children were randomly selected to participate in the control group $\left(M_{\mathrm{age}}=\right.$ 6.86 years, $S D=1.47$; females $=34$; males $=30$ ). Pre- and post-testing took part during a 2 -week period before and immediately following the intervention.

\section{Overview of the teacher intervention and rationale for including each component}

The teacher intervention occurred over 5 days spread out over a 3-month period. All meetings were held in the school's library and facilitated by authors Hawes, Merkley, and Ansari, with additional expertise provided by Lien Peters. As shown in Figure 1, the focus of the first two sessions was on the foundations of number, the third session focused on number-space associations, and the fourth and fifth sessions focused on arithmetic (addition and subtraction) strategies. Table 1 provides a summary of the main mathematical content/concepts addressed across sessions. Although each day had its own focus, the general structure of each session was the same and, as reviewed next, was comprised of the same five components: (1) a researcher-led presentation of numerical cognition research (e.g., arithmetic strategies), (2) a group discussion of one or two research articles, (3) assessments of students' mathematical thinking via clinical interviews, (4) teacher engagement with mathematics, and (5) design and

Table I. Summary of main mathematical content addressed across each session

\begin{tabular}{|c|c|}
\hline $\begin{array}{l}\text { Session } \\
\text { number }\end{array}$ & Main numerical content addressed \\
\hline \multirow[t]{4}{*}{$\mathrm{I} / 2$} & Overview of counting principles \\
\hline & Place value \\
\hline & Overview of arithmetic strategies \\
\hline & Main focus on cardinality and ordinality \\
\hline \multirow[t]{3}{*}{3} & Number-space mappings \\
\hline & Grids/Coordinates \\
\hline & $\begin{array}{l}\text { Main focus on number lines as a tool for assessment, understanding, and representing } \\
\text { numerical relations }\end{array}$ \\
\hline \multirow[t]{2}{*}{$4 / 5$} & $\begin{array}{l}\text { Arithmetic strategies (counting up, counting on, composing/decomposing, automatic } \\
\text { retrieval) }\end{array}$ \\
\hline & Main focus on composing/decomposing number and building arithmetical fluency \\
\hline
\end{tabular}


implementation of student activities/lessons. For complete details and the scheduling of each session visit: https://osf.io/tqs7e/?view_only=f54807cfc99245ed8d1a8b256b 142187

Researcher-led presentation of numerical cognition research

During the morning of each session, one or several of the research team members (Hawes, Merkley, Ansari, Peters) prepared and presented a brief presentation on the day's given theme (e.g., numerical foundations). Examples of topics from numerical cognition research included research on the counting principles, dyscalculia, number line training studies, and arithmetic strategies (a more detailed description of the specific topics is addressed further below). Examples of topics on developmental cognitive (neuro)science included sharing and discussing research related to distributed/spaced practice effects, neuromyths, conceptual versus procedural knowledge, brain plasticity, and effects of home and environment on early academic achievement. Moreover, discussing research in these various areas naturally led to sharing and discussing various other terms frequently used in cognitive science research, including inhibitory control, executive functions, and working memory.

The purpose of these presentations was to introduce and share research findings from the field of numerical cognition as well as developmental cognitive neuroscience more generally. More specifically, by sharing, translating, and discussing research it was our intent to provide a springboard from which to focus our collective thinking and theorizing about children's numerical thinking and the types of classroom activities that relate to such research findings. We saw these presentations as an opportunity to initiate a group discussion on whether and how research in numerical cognition is or can be applied to the classroom. The central topic of these presentations also served as the focal point and unifying feature of all other aspects of the professional learning across each session.

This specific component of the intervention was hypothesized to facilitate teachers' understanding of research knowledge and terminology related to numerical cognition and, to a lesser degree, developmental cognitive neuroscience more generally. For this reason, we expected to see gains on a test and self-report measure of numerical cognition knowledge, as well as potentially increases in self-perceived general cognition terminology (see measures below).

\section{Whole-group discussion of research articles}

Between sessions, group members were expected to read one or two research articles related to the session's main topic. Table 2 provides a list of the articles read and discussed. Group members prepared questions based on the reading(s), providing a catalyst for the group discussion of the readings. This component of the intervention was designed to serve the same purpose as the researcher-led research presentation. It was our intention that reading and discussing research in numerical cognition would help familiarize group members with key concepts and terminology from the field of numerical cognition. We also viewed this component as an extension of the research presentations and an opportunity for group members to further consolidate and question their understanding of the targeted topics. This component was hypothesized to further facilitate teachers' content knowledge in the area of numerical cognition as well as issues related to bridging the gap between research and practice. 
Table 2. List of articles read and discussed as part of teacher professional learning intervention

\begin{tabular}{llll}
\hline $\begin{array}{l}\text { Session } \\
\text { number }\end{array}$ & Title of research article & Year & Author(s) \\
\hline 2 & Numerical Symbols Count for Mathematical Success & 2017 & $\begin{array}{c}\text { Merkley \& } \\
\text { Ansari }\end{array}$ \\
3 & $\begin{array}{c}\text { Laying the Foundation for Computational Fluency } \\
\text { Improving the Numerical Understanding of Children from Low- } \\
\text { Income Families }\end{array}$ & 2003 & $\begin{array}{c}\text { Griffin } \\
\text { Siegler }\end{array}$ \\
4 & $\begin{array}{c}\text { Early Number Competencies and Mathematical Learning: } \\
\text { Individual Variation, Screening, and Intervention }\end{array}$ & 2014 & $\begin{array}{c}\text { Jordan, Fuchs, \& } \\
\text { Dyson }\end{array}$ \\
5 & $\begin{array}{c}\text { Bridges Over Troubled Waters: Education and Cognitive } \\
\text { Neuroscience }\end{array}$ & 2006 & $\begin{array}{c}\text { Ansari \& Coch } \\
\end{array}$ \\
\hline
\end{tabular}

Assessments of students' mathematical thinking

As a follow-up to research on children's numerical thinking, as well as a means to bridge between research and practice, we carried out brief assessments of children's mathematical thinking (i.e., clinical interviews). These assessments were based on established measures within the numerical cognition literature and targeted the session's given focus. During our session on the foundations of numerical thinking, team members were provided with a copy of Okamoto and Case's Number Knowledge Test (Okamoto \& Case, 1996) and administered the assessment with a minimum of three of their own students. During the session where we investigated numerical-spatial associations, teachers were introduced to the number line task (i.e., a task involving the placement of a given number on a horizontal line marked with bounded end points, e.g., 0 and 100). During the sessions on arithmetic, teachers were introduced to methods of observing and recording children's arithmetic strategy use. With the exception of the Number Knowledge Test, which occurred in between sessions, the other assessments occurred as part of the professional learning. Following the assessments, we would come back together as a group and take turns sharing our observations of student thinking. Teachers were also encouraged, whenever possible, to video record their interviews and assessments with students and later upload them to our group's shared Google Drive. Teachers were given opportunities to show a brief video clip of their students' thinking and discuss it with the group.

The primary purpose of this component of the intervention was to make students' mathematical thinking visible, providing teachers with new insights into students' mathematical thinking (Ginsburg, 1997). Relatedly, it was our hope that these observations/insights would help inform subsequent teacher planning and instruction in the given areas of focus. For these reasons, teachers were encouraged to carry out the assessments as clinical interviews as opposed to standard test administration. In other words, we encouraged teachers to focus less on test administration and more on what the child's response to the question might reveal about their current mathematical understanding. We encouraged the group to 'go off script' and improvise new questions and extensions in direct response to the child's responses.

By orienting attention towards student thinking (and what this might mean for instruction), we predicted that teacher-student interviews/assessments may confer a number of benefits. In line with previous research, we predicted that teacher-student 
interviews/assessments may enhance teachers' mathematical content knowledge as well as pedagogical content knowledge (Ball, Thames, \& Phelps, 2008; Clarke, Clarke, \& Roche, 2011; Mast \& Ginsburg, 2010; Moss et al., 2015). Moreover, the use of teacherstudent interviews has also been associated with increased teacher confidence in teaching mathematics (Clarke et al., 2011). For these reasons, we had reason to believe that the inclusion of teacher-student assessments was an important potential agent of teacher change.

\section{Teacher engagement with mathematics}

During each meeting, teachers engaged in a variety of mathematical activities related to each session's targeted theme (e.g., number-space associations). While some of these activities were specifically intended for adults, the majority of the activities were intended to be implemented in the teachers' classrooms with their own students. In other words, with few exceptions, the activities that we asked teachers to engage in were the same as those that were to be implemented with students in the teachers' own classrooms (reviewed in the next section). This component of the intervention was designed to achieve several related aims. First, it was as a means of focusing attention on student thinking - a guiding principle of our approach to PD. Teachers were asked to engage in the activities with the perspective of their students in mind (e.g., 'How might you approach this task if you were a student? If you were a 5-year-old what might you find difficult? What questions might you have?'). A second purpose of having teachers engage in mathematics was to increase content knowledge and to further raise the group's familiarity with the concepts discussed previously in the context of research. For example, by engaging in an activity targeting various arithmetic strategies (e.g., counting on from the largest of two addends), it was hoped that teachers would become better acquainted with concepts related to arithmetic strategies, and in turn, would better able to recognize their students' arithmetic strategies. A third purpose of doing mathematics as a group was an attempt to lower teachers' mathematics anxiety. It is well documented that early years teachers demonstrate high levels of mathematics anxiety, that is, feelings of fear or apprehension of mathematics or the prospect of doing math (see Schaeffer et al., 2020). We intentionally selected activities that we thought would give teachers a new appreciation for mathematics and that they would be excited to share with their students. Moreover, by having teachers engage in mathematics through the mind of a child, we aimed to make it clear that we were not evaluating the teachers' mathematical performance, but rather, we were interested in learning more about how children think about and learn mathematics.

To summarize, this component of the intervention was intended as a means to (1) orient teachers' attention towards students' mathematical thinking, (2) to increase mathematical content knowledge, and (3) foster positive attitudes towards mathematics (i.e., lower levels of math anxiety). In addition, we anticipated that teachers would be more likely to implement the activities in their classrooms if they were more familiar with the tasks and had formed certain expectations and ways of observing student reasoning during implementation.

\section{Design and implementation of student intervention}

The last component of the teacher intervention centred around the implementation of classroom-based activities. Each session, the research team presented the teacher team with a series of activities aligned with the session's targeted focus (e.g., number-space 
associations). As noted above, these activities were first presented to and tried by the teacher team. Then, as a team, we discussed how the activities might be implemented and, if necessary, adapted, in the teachers' own classrooms. To access the activities for each session visit: https://osf.io/tqs7e/?view_only=f54807cfc99245ed8d1a8b256b142187.

The activities were referred to as Quick Challenge activities and, as the name suggests, were designed as brief (5-20 min) activities that could easily be implemented and continually adapted over multiple iterations. That is, the Quick Challenge activities were not designed to be stand-alone lessons, but activities that could be used and continually adapted to meet the learning needs of children in different grades (K-3) and abilities. For example, both the arithmetic and number line activities can easily be adapted and extended by using a different range of whole numbers (as well as different supporting materials, such as manipulatives). The specific number ranges and problem types used for each activity were based on the assessments described above, the teacher's own knowledge of their students, and grade-level expectations outlined by the Ontario math curriculum (https://www.dcp.edu.gov.on.ca/en/curriculum\#elementary).

For example, according to the curriculum, students in Grade 1 are expected to use 'mental math strategies, including estimation, to add and subtract whole numbers that add up to no more than 20, and explain the strategies used' (https://www.dcp.edu.gov.on.ca/ en/curriculum/elementary-mathematics/grades/g1-math/strand-b/b2). This same curriculum expectation exists for students in Grades 2 and 3, but with a different target number in place. Thus, while students in kindergarten might carry out arithmetic and number line activities using whole numbers ranging from 0 to 10 , students in Grade 2 might engage in the same activities but with numbers ranging from 0 to 100 . The selected activities were intended to build-up children's numerical reasoning gradually and in accordance with the principle of distributed/spaced practice (Kang, 2016; Rohrer, 2015). In fact, we presented and discussed research on distributed/spaced practice as a means to first introduce the group to Quick Challenge activities and the rationale for their design and implementation.

In terms of implementation, teachers were encouraged to try all of the shared activities as part of their regular mathematics instructional time. Teachers were provided with log sheets to record notes and the name and duration of the Quick Challenge activities implemented. During each meeting, with the exception of the first one, teachers shared the successes and challenges they faced with implementation.

We predicted that having students participate in these activities throughout the intervention would (1) provide a context in which teachers could further observe the concepts discussed as part of the professional learning and (2) provide opportunities for students' to further strengthen their numerical reasoning. More specifically, given the content of the Quick Challenge activities, we expected to see the largest evidence of student gains in their basic numerical reasoning (number comparison and ordering), mental arithmetic, number line estimation, and abilities to apply their numerical knowledge across a variety of number-based contexts

\section{Pre- and post-test measures}

Teacher measures and testing procedure

Math anxiety. Teacher mathematics anxiety was measured using the short Mathematics Anxiety Rating Scale (sMARS; Alexander \& Martray, 1989). The questionnaire includes 25 items. For each item, participants are asked to indicate the degree to which a given math- 
related situation (e.g., receiving a math textbook, being given a set of subtraction problems to solve on paper) would make them feel anxious on a 5-point scale, from 'not at all' to 'very much'. Each teacher received a total score across all 25 items. To keep the total scores meaningful and within the 5-point rating scale, we divided each teacher's total score by 25 . Thus, each teacher was given a score out of 5 , with lower scores indicating lower math anxiety and higher scores indicating higher math anxiety. ${ }^{1}$

Math comfort level. As an additional means of measuring teacher mathematics comfort/ anxiety, teachers completed the Math for Young Children Survey (see Hawes et al., 2017). The survey includes nine items in which teachers are asked to indicate their comfort-level teaching and learning math on a 5-point scale, from 'not at all comfortable' to 'very comfortable' (e.g., How comfortable are you teaching math? How comfortable are you as a math learner?). Each teacher received a total score across all nine items. To keep the total scores meaningful and within the 5-point rating scale, we divided each teacher's total score by 9 . Thus, each teacher was given a score out of 5, with lower scores indicating lower comfort levels with math and higher scores indicating higher levels of comfort with math.

Numerical cognition test. This test was specifically designed for the purposes of this study. The test includes 12 multiple choice questions on key topics and concepts discussed within the numerical cognition literature and addressed within the current intervention. For example, the measure assesses knowledge of concepts and terms related to arithmetic strategies, numerical distance effects, the 'mental number line', the counting principles, and dyscalculia (for a copy of the test see: https://osf.io/tqs7e/?view_only=5d $72 \mathrm{f83ffcf} 1430093 \mathrm{bcc} 3 \mathrm{c0d} 15 \mathrm{fd} 34 \mathrm{e}$ ). One point was awarded for each correct response on the test, and teachers were given a total score out of 12 .

Self-perceived numerical cognition knowledge. This measure consisted of five items from the Mind, Brain, and Education Questionnaire (Goffin et al., 2018). Participants were presented with terms related to numerical cognition, such as dyscalculia, cardinality, mental number line, and asked to indicate their level of knowledge on a 6-point scale: "None" means you have never heard of the term and "Excellent" mean you could explain the term to a peer'. Each teacher received a total score out of 30 . To keep the total scores meaningful and within the 6-point rating scale, we divided each teacher's total score by 5 . Thus, each teacher was given a total score out of 6 to indicate their self-perceived numerical cognition knowledge, with lower scores indicating lower self-perceived knowledge and higher scores indicating higher self-perceived knowledge.

Self-perceived general cognition knowledge. This measure consisted of the remaining nine items from a subsection of the Mind, Brain, Education Questionnaire noted above. Participants were presented with terms related to cognitive science research more

' Details on missing data across measures ca can be accessed here: $h$ ttps:/losf.io/tqs 7e/files/?view_only=f54807cfc99245ed8d $|a 8 b 256 b / 42| 87$. 
broadly, including brain plasticity, working memory, dyslexia, executive functions, and the scientific method. The same 6-point scale and scoring procedures described above were used. Thus, each teacher was given a total score out of 6 to indicate their selfperceived general cognition knowledge, with lower scores indicating lower selfperceived knowledge and higher scores indicating higher self-perceived knowledge.

\section{Child measures and testing procedure}

Participating children completed 13 measures over two approximately 30-min testing sessions (1-5 days a part) 2-3 weeks prior to the intervention and within a 2-week period following the intervention. With the exception of the Mental Arithmetic measure, which was designed specifically for this study, all measures were selected from published research. Participants completed the measures in pseudo-random order due to the blocked nature of some of the tests. Symbolic Number Comparison, Non-symbolic Number Comparison, and Ordering were administered to children in this order. Children also always completed the Path Span Forward prior to Path Span Reverse and Numeration prior to Geometry. All testing occurred at a quiet location in the school and was administered one-to-one by trained experimenters. For descriptions of the spatial and executive function skills measures, please visit the following the link: https://osf.io/ tqs7e/?view_only=5d72f83ffcf1430093bcc3c0d15fd34e.

We had a priori reasons to believe that students would make the largest gains on the measures of numerical and mathematical reasoning (see our preregistered hypotheses: https://osf.io/tqs7e/registrations). Specifically, we predicted that the largest gains would occur on the following measures given our explicit focus on these aspects of numerical reasoning throughout the teacher PD (e.g., see Table 1; for a detailed overview and schedule of each day of PD see: https://osf.io/3baev/): symbolic comparison, ordering, arithmetic, number line estimation, and overall numeration. These aspects of numerical reasoning were also the focus of the student intervention activities (see https://osf.io/ 2qzh6/). We had few reasons to expect student gains on the measures of spatial reasoning and executive function. Instead, these variables served the purpose of measuring the specificity of intervention effects.

\section{Measures of numerical and mathematical reasoning}

The first three measures described below were adopted from Lyons, Bugden, De Jesus, and Ansari (2018) and Lyons, Hutchison, Bugden, Goffin, and Ansari (2018) and part of the same paper-and-pencil measure. As noted above, these three measures were presented in fixed order. Both the symbolic and non-symbolic number comparison tasks consisted of 72 items, and the ordering task included 48 items. Children were provided with 1 min to complete as many items as possible. For all three measures, the same scoring procedures were used. To adjust for potential speed-accuracy trade-offs/guessing behaviour, adjusted raw scores were computed by subtracting the total number of incorrect items from the total number of correct items (see. Lyons, Bugden, et al., 2018; Lyons, Hutchison, et al., 2018).

Symbolic number comparison. Children were presented with pairs of Hindu-Arabic numerals (e.g., 215) and asked to indicate the larger number as quickly and accurately as possible. Comparisons were confined to single-digit numerals (1-9), and the absolute 
distances between numerals ranged from 1 to 3 . Trials were counterbalanced so that the larger number appeared an equal number of times on the left side of the page as the right.

Non-symbolic number comparison. Children were presented with pairs of dot arrays (e.g., : । ::) and asked to indicate the array with the most dots as quickly and accurately as possible. Dot arrays ranged from 1 to 9 dots and included the same numerical distances as those used in the symbolic number comparison task. Children were instructed not to count the dots. To control for the influence of the continuous properties of the dot stimuli on performance, both the area and contour length were manipulated and controlled for across trials. On half the trials, dot area was positively correlated with numerosity and overall contour length was negatively correlated. The reverse was true on the other half of the trials.

Ordering task. Children were presented with a sequence of numerals (e.g., $1-2-3$ ) and asked to indicate whether or not the sequence was in numerical order. Numerals ranged from 1 to 9 and included absolute numerical distances of 1 (e.g., $1-2$ - 3) or 2 (e.g., $1-3-5)$. There were an equal number of correct and incorrect sequences of distances 1 and 2. For half of the items, the sequences were in the correct 'ascending order', and for the other half, the sequences were in incorrected order.

Mental arithmetic. Children were asked 12 addition problems of increasing difficulty. The first four problems were considered 'easy' and involved solutions with sums of five or less. The next four problems were considered 'medium' difficulty and involved solutions between 6 and 10. The last four problems were considered 'difficult' and involved solutions between 11 and 15. Questions were counterbalanced so that on half of the questions the smaller addend was presented first (e.g., $1+2)$ and on the other half the larger addend was presented first (e.g., $2+1$ ). Children were provided with no external aids (e.g., paper and pencil, manipulatives) and verbalized their responses to each question. Children were awarded 1 point for each correct response and given a total score out of 12 .

Number line estimation. This measure was administered on an iPad (to access the application see: https://hume.ca/ix/estimationline.html). Children were presented with a horizontal line marked with ' 0 ' at the far left end of the line and either '10' or '100' at the far right end of the line. Kindergarten children were administered the $0-10$ number line, and children in Grades 1-3 were administered the 0-100 number line. The goal of the task was to indicate where on the line a given target number belongs (e.g., 'Where does the number six belong on the line?'). To familiarize children with the task, children were first presented with a practice trial: For kindergarten children, the practice trial involved the placement of ' 5 ', and for children in Grades 1-3, the practice trial involved the placement of ' 50 '. The test trials for kindergarten children included numbers 1-9 (with the exception of 5). For children in Grades 1-3, test trials included the following target numbers adopted from Laski and Siegler (2007): 2, 3, 5, 8, 12, 17, 21, 26, 34, 39, 42, 46, 54, 58, 61, 67, 73, 78, $82,89,92$, and 97. All trials were randomly presented to children. The accuracy of each trial was recorded by the computer. We then used this information to calculate each child's overall accuracy across all estimates. To do this, we calculated each child's per cent 
absolute error (PAE) using the following formula. Note that a lower PAE is associated with greater accuracy (less error).

$$
\text { PAE }=\left|\frac{\text { Estimate }- \text { Estimate Quantity }}{\text { Scale of Estimates }}\right| \times 100 .
$$

Numeration test. Children's overall numeracy performance was assessed with the Numeration subtest from KeyMath (Connolly, 2007); a standardized Canadian normed test designed for students in kindergarten to 12 th grade. This test provides a comprehensive and curriculum-aligned assessment of children's numeration skills, including knowledge and concepts related to counting, comparing quantities, recognizing and ordering number symbols, operations, place value, and proportions/fractions/decimals. The test includes 49 items in total. Children were given a total raw score by subtracting the total number of incorrect responses from the maximum item number reached.

Geometry test. To assess children's geometry performance, we used the Geometry subtest from the KeyMath assessment described above (Connolly, 2007). This test provides a comprehensive and curriculum-aligned assessment of children's geometry skills, including knowledge and concepts related to shape recognition, positional language, geometrical transformations (e.g., rotations), measurement, grid coordinates, angles, and geometric proofs. The same scoring procedures described above were used for this measure. The test included a total of 36 items.

\section{Measurement of time spent implementing teacher-led student intervention activities}

Teachers in the intervention groups were provided with tracking sheets where they recorded the date, duration, name of activity, and a brief description of all activities conducted. It is worth noting that in each participating school (including the control group), teachers of Grades 1-3 reported adhering to the Ontario Ministry of Education policy of teaching mathematics for $60 \mathrm{~min} /$ day. More specifically, in each school, the class schedule was structured to ensure one 60-min block of mathematics per day. While there is no mandate or guideline for how much time should be devoted to mathematics instruction in kindergarten, all participating schools reported between 30 and 45 min of mathematics instruction per day. Thus, each school engaged in approximately equivalent amounts of mathematics instruction.

As noted above, teachers were also encouraged to contribute to the group's shared Google Drive. Specially, teachers were encouraged to upload any videos of teacher-led assessments, pictures/videos of student work based on the teacher-led student activities, and any adapted versions of the activities tried by teachers in their own classrooms. Both intervention groups were provided with a total score based on the number of unique items uploaded. We then used this score as an exploratory means of measuring and comparing the intervention groups' engagement and/or commitment to the project.

\section{Analytical approach}

Analyses were based on the analytical approaches outlined in the pre-registration of the Year 1 (https://osf.io/efyqy) and Year 2 studies (https://osf.io/qrih3). Data were analysed using 
Bayesian statistics and conducted with JASP (version 0.9.0.1). Findings from both the preliminary and main analyses are reported using Bayes factors: A statistic that provides a means of directly comparing and evaluating the strength of evidence for one statistical model over another (e.g., a model with a group $\times$ time interaction vs. a model without this interaction term). One of the benefits of using Bayes factors is that they provide a means to quantify the amount of support both for and against the alternative hypothesis over the null. Moreover, Bayes factors can be used to indicate when there is insufficient evidence in support of the alternative hypothesis or the null. Knowing whether there is support for the null and/or whether more data are needed before claiming support for the null is especially important when analysing and reporting intervention-based research. Another advantage of using Bayesian statistics, compared to traditional frequentist statistics, is that smaller sample sizes are needed to reach conclusions about the presence of a given effect, while having the same or lower long-term error rate (Schönbrodt, Wagenmakers, Zehetleitner, \& Perugini, 2017). Given the small sample size of teacher participants in the present study, Bayesian analyses were ideally suited for this purpose.

For all preliminary analyses, we report on Bayes factors as they correspond to evidence in favour of the alternative hypothesis (i.e., that there are differences between groups at pre-test) compared with the null hypothesis (i.e., there are no differences between groups at pre-test). For these analyses, the symbol $\mathrm{BF}_{10}$ is used to signify the strength of evidence for the alternative hypothesis (H1) over the null (H0). As detailed further below, we considered Bayes factors of 3 and above as evidence for the alternative (i.e., the presence of group differences at pre-test).

To address our main questions of whether or not the intervention had any positive effects on both teacher and student outcomes, we used mixed-design Bayesian repeatedmeasures ANOVA. In both Studies 1 and 2, Bayesian repeated-measures ANOVA was used to analyse the extent to which the intervention and control groups changed in relation to one another from pre- to post-test. More specifically, we conducted a group (intervention vs. control) by time (pre vs. post) analysis for each dependent variable. Note that this approach was used for all main analyses reported below. In addition, in Year 2 we also evaluated the effects of the intervention by carrying out within-group Bayesian repeated-measures ANOVAs. In all cases, we report on the Bayes factors from a model with the interaction term (group $\times$ time) from models without the interaction term. More specifically, we report on the statistic referred to as Bayes factor inclusion (hereafter $\mathrm{BF}_{\text {incl }}$ ). The $\mathrm{BF}_{\text {incl }}$ provides a means to quantify the amount by which the prior odds of including an effect term in the model (in this case a group $\times$ time interaction) is updated after observing the data. For example, a $\mathrm{BF}_{\text {incl }}$ of 5 indicates that the observed data have increased the odds of an interaction by a factor of 5 . Said differently, a model which includes the interaction term is five times more likely than all other models of the data that do not contain an interaction.

The following guidelines for interpreting the strength of Bayes factors have been recommended (e.g., see Jarosz \& Wiley, 2014): Bayes factors between 1 and $3=$ weak/ anecdotal support (not enough evidence to make any substantial claims either for or against the predicted relationship); Bayes factors between 3 and $10=$ substantial support (enough evidence to make moderate claims about effect); Bayes factors between 10 and $100=$ strong evidence (enough evidence to be make moderate/strong claims about effect); Bayes factors greater than $100=$ very strong/decisive evidence (enough evidence to make strong claims about effect). As mentioned above, in the present study, we report on the Bayes factors associated with a model that includes an interaction compared with all other models that do not include the interaction term. In cases where the reported Bayes factors are below 1 , this is an indication that there is more support for a model that 
does not include an interaction factor. In cases where the Bayes factor is 3 or above, this is considered evidence in support of an interaction. In short, the higher the Bayes factor, the higher the odds of there being a group difference from pre-to-post.

\section{Results}

\section{Year I - teacher results}

\section{Preliminary analyses}

To assess the presence of any group differences at pre-test on any of the measures, a series of Bayesian independent samples $t$-tests were conducted (see Table 3). Results revealed no evidence of group differences on any of the five pre-post-measures, suggesting that the groups were well-matched on all measures of interest. Note that these analyses did not include data from the school principals from either group. This was due to missing or incomplete data.

\section{Main analyses}

A comparison of pre-post-gains can be seen in Table 3 and Figure 2. Our analyses indicated evidence of pre-post-gains by the intervention group compared with the control group on three measures: Numerical Cognition Knowledge (20), $\mathrm{BF}_{\text {incl }}=9.24$; Self-Perceived Numerical Cognition Knowledge (21), $\mathrm{BF}_{\text {incl }}=7.47$; Self-Perceived General Cognition Knowledge $(21), \mathrm{BF}_{\text {incl }}=11.64$. On both the Math Comfort Level and Math Anxiety surveys, there was evidence in favour of the null (i.e., support against a model that includes a time $\times$ group interaction); Math Comfort Level (16), $\mathrm{BF}_{\text {incl }}=0.25$; Math Anxiety (16), $\mathrm{BF}_{\text {incl }}=0.19$. Note that the numbers in brackets refer to the degrees of freedom for each ANOVA conducted. Figure 2 displays each teacher's individual scores on each measure and across each time point.

\section{Year I - student results}

\section{Preliminary analyses}

Table 4 shows the mean scores and standard deviations by group at pre and post. To assess the presence of any group differences at pre-test on any of the measures (as well as age), a series of Bayesian independent samples $t$-tests were conducted. No group differences were observed on any of the measures, suggesting that the groups were well-matched in terms of age and performance at pre-test.

Table 3. Mean scores and standard deviations by teacher group at pre- and post-test (Year I)

\begin{tabular}{llllll}
\hline & $\begin{array}{l}\text { Math } \\
\text { comfort }\end{array}$ & Math anxiety & $\begin{array}{l}\text { Num. cog. } \\
\text { knowledge } \\
\text { test }\end{array}$ & $\begin{array}{l}\text { Self-perceived } \\
\text { num. cog. } \\
\text { knowledge }\end{array}$ & $\begin{array}{l}\text { Self-perceived } \\
\text { gen. cog. } \\
\text { knowledge }\end{array}$ \\
\hline $\begin{array}{l}\text { Pre-test } \\
\quad \text { Experimental }\end{array}$ & $25.82(5.08)$ & $82.64(15.27)$ & $7.43(1.45)$ & $14.67(6.20)$ & $28.53(9.16)$ \\
$\quad \begin{array}{l}\text { Control } \\
\text { Post-test }\end{array}$ & $27.57(6.32)$ & $92.14(15.60)$ & $6.75(1.39)$ & $15.63(4.27)$ & $27.75(6.45)$ \\
$\quad \begin{array}{llll}\text { Experimental } \\
\text { Control }\end{array}$ & $25.33(5.25)$ & $84.27(19.52)$ & $8.93(1.83)$ & $19.00(3.51)$ & $44.33(8.17)$ \\
\hline
\end{tabular}



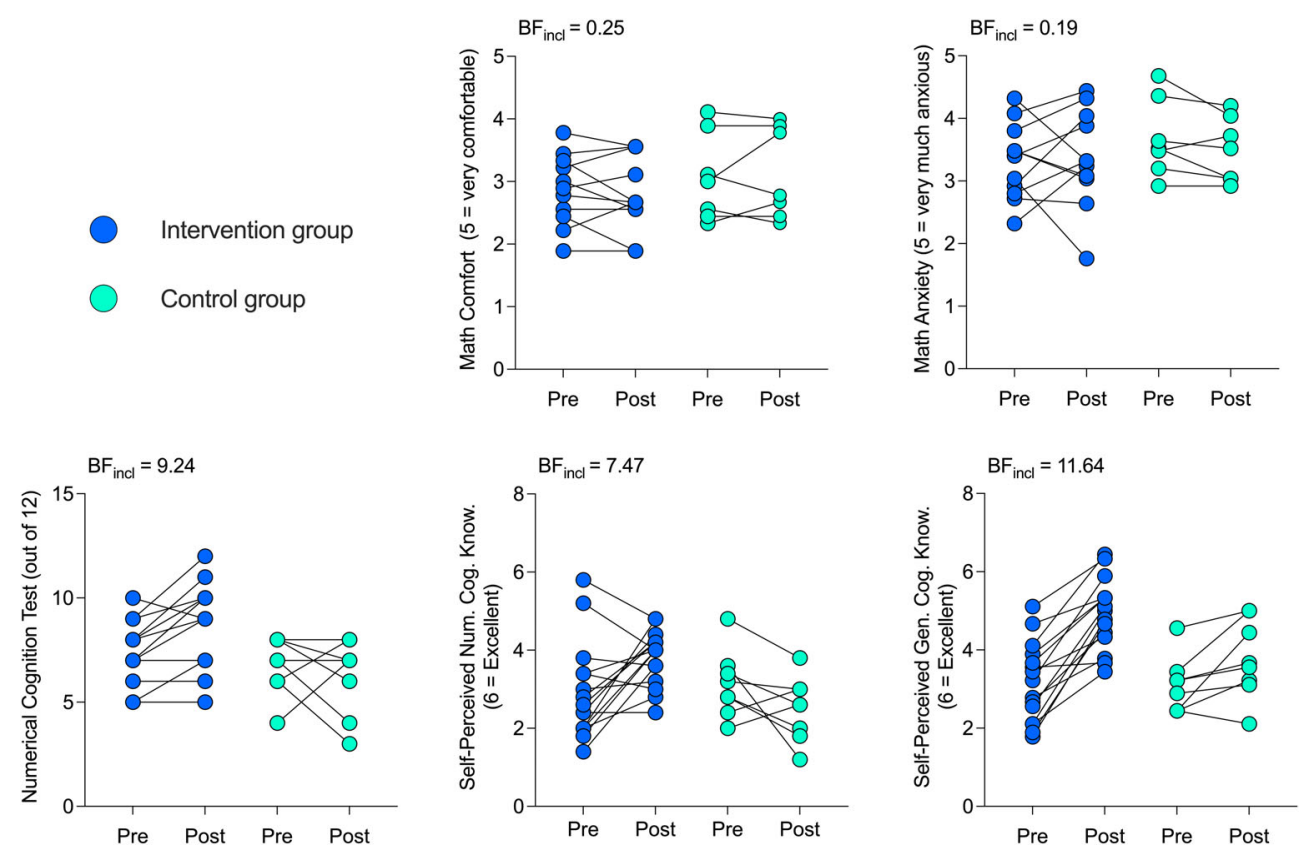

Figure 2. Comparison of pre-post-performance by teachers in the intervention and control groups (Year I). Each pair of circles connected by a line represents the pre-post-scores for an individual teacher.

\section{Main analyses}

A comparison of pre-post-gains can be seen in Table 4 and Figure 3. Our analyses indicated evidence of pre-post-gains by the intervention group compared with the control group on three measures: Numeration(104), $\mathrm{BF}_{\text {incl }}=9.65$; Arithmetic(104), $\mathrm{BF}_{\text {incl }}=8.50 ;$ Number Line $(\mathrm{PAE})(97) ; \mathrm{BF}_{\text {incl }}=4.53$. There was evidence of pre-postgains in favour of the control group on the Non-symbolic Number task (105), $\mathrm{BF}_{\text {incl }}=28.40$. There was no evidence of group differences from pre-to-post on any of the other measures: Geometry(102), $\mathrm{BF}_{\text {incl }}=0.06$; Symbolic Number Comparison(105), $\mathrm{BF}_{\text {incl }}=0.44$; Ordering(105), $\mathrm{BF}_{\text {incl }}=0.07$; Visual-Spatial Working Memory - Forward Path Span(98), $\mathrm{BF}_{\text {incl }}=0.22$; Visual-Spatial Working Memory - Reverse Path Span(98), $\mathrm{BF}_{\text {incl }}=0.31$; Head-Toes-Knees-Shoulders(104), $\mathrm{BF}_{\text {incl }}=0.21$; Raven's Matrices(104), $\mathrm{BF}_{\text {incl }}=0.34 ; 2 \mathrm{D}$ Mental Rotation(104), $\mathrm{BF}_{\text {incl }}=0.23$; Visual-Spatial Reasoning(104), $\mathrm{BF}_{\text {incl }}=0.23$. Figure 3 shows all children's pre-post-scores by group and across all the mathematics measures (to view pre-post-scores by group for performance on the spatial and EF measures visit; https://osf.io/e4rzy/view_only=f54807cfc99245ed8d1a8b256b 142187).

\section{Summary of Year I results}

Teachers in the intervention group demonstrated greater gains than the control group on measures of numerical cognition knowledge, self-perceived numerical cognition knowledge, and self-perceived general cognition knowledge. There was support in favour of an absence of gains (i.e., support for the null) on measures of math anxiety and comfort in the 


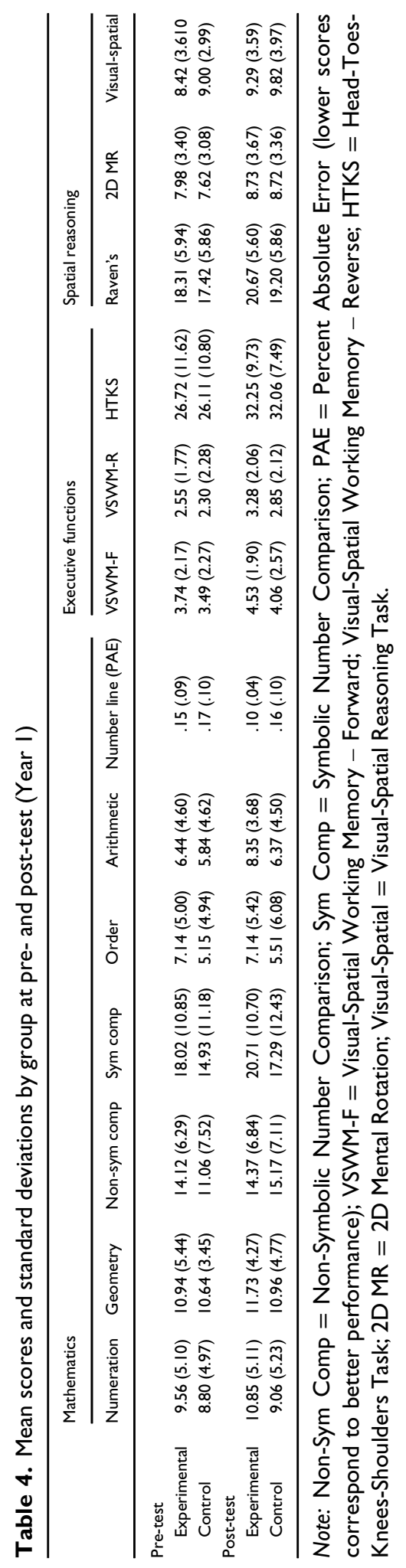


Intervention Group

Control Group
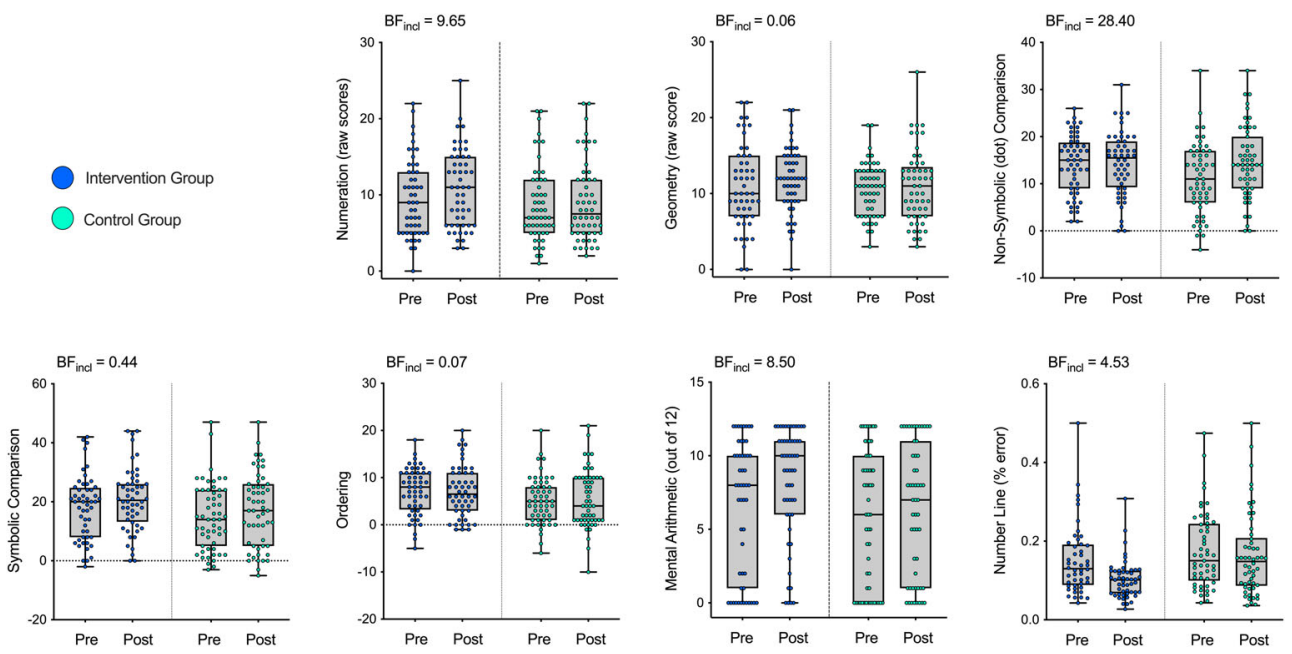

Figure 3. Comparison of pre-post-performance by students in the intervention and control groups (Year I). Each circle corresponds to an individual child's data point.

teaching and learning of mathematics. Children in the intervention classrooms demonstrated greater gains compared with the control group on measures of number line estimation, mental arithmetic (addition), and overall numeration performance. Both groups of children made highly similar gains on measures of spatial and EF skills, which were not targeted during PD. Thus, the gains made by the intervention group were highly specific to content and activities covered as part of the teacher PD.
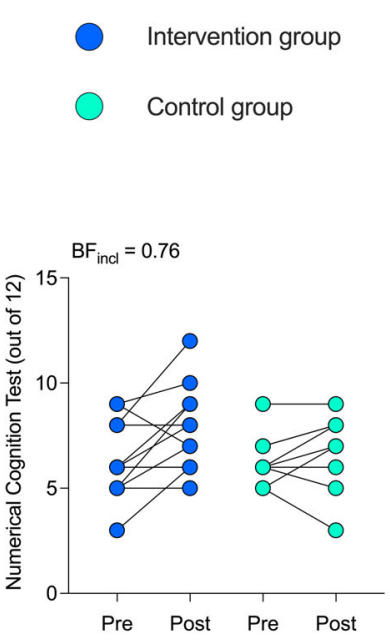
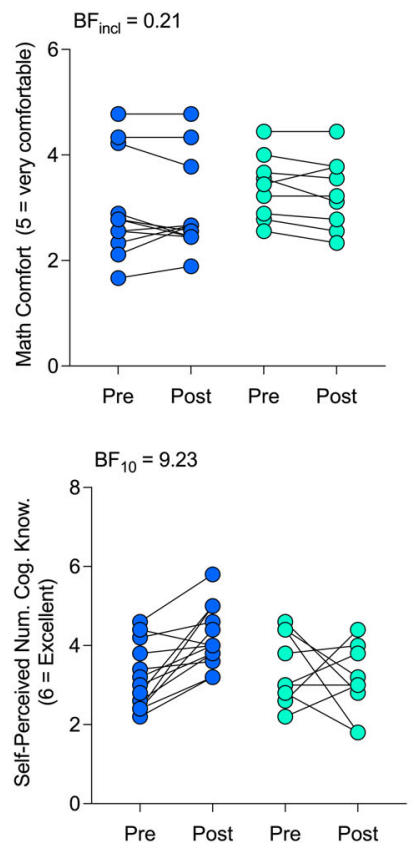
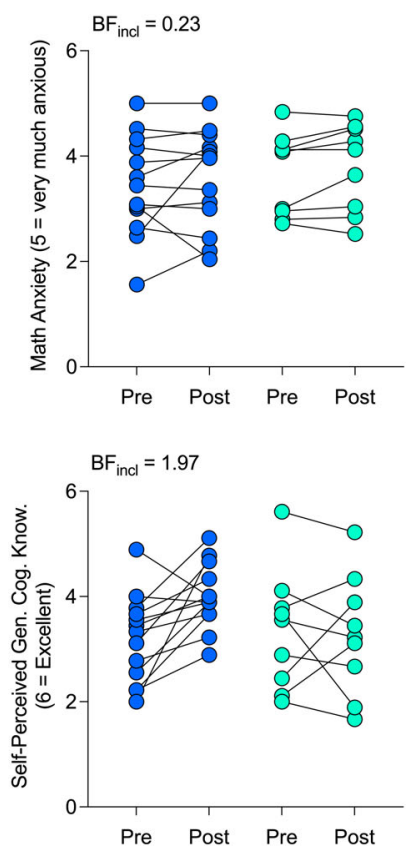

Figure 4. Comparison of pre-post-performance by teachers in the intervention and control groups (Year 2). Each pair of circles connected by a line represents the pre-post-scores for an individual teacher. 
Year 2 - teacher results

Preliminary analyses. Results revealed no evidence of group differences on any of the five pre-post-test measures (see Table 5), suggesting that the groups were well-matched on all measures of interest.

Main analyses. Table 5 shows the mean scores and standard deviations by group at pre and post. On both the Math Comfort Level and Math Anxiety surveys, there was evidence in favour of the null (i.e., support against models that included the time $\times$ group interaction); Math Comfort Level (19), $\mathrm{BF}_{\text {incl }}=0.21$; Math Anxiety (20), $\mathrm{BF}_{\text {incl }}=0.23$. Support for the presence of a group by time interaction in favour of the intervention group was observed on the measure of Self-Perceived Numerical Cognition Knowledge (20), $\mathrm{BF}_{\text {incl }}=9.23$. There was insufficient evidence for or against a group $\times$ time interaction on the remaining two measures: Numerical Cognition Knowledge (20), $\mathrm{BF}_{\text {incl }}=0.76$; SelfPerceived General Cognition Knowledge $(20), \mathrm{BF}_{\text {incl }}=1.97$. Figure 4 displays each educator's individual scores on each measure and across each time point.

Table 5. Mean scores and standard deviations by teacher group at pre- and post-test (Year 2)

\begin{tabular}{llllll}
\hline & $\begin{array}{l}\text { Math } \\
\text { comfort }\end{array}$ & Math anxiety & $\begin{array}{l}\text { Num. cog. } \\
\text { knowledge } \\
\text { test }\end{array}$ & $\begin{array}{l}\text { Self-perceived } \\
\text { num. cog. } \\
\text { knowledge }\end{array}$ & $\begin{array}{l}\text { Self-perceived } \\
\text { gen. cog. } \\
\text { knowledge }\end{array}$ \\
\hline $\begin{array}{l}\text { Pre-test } \\
\quad \text { Experimental }\end{array}$ & $26.83(8.58)$ & $86.00(23.60)$ & $6.46(1.8 I)$ & $15.92(4.15)$ & $28.77(7.44)$ \\
$\begin{array}{l}\text { Control } \\
\text { Post-test }\end{array}$ & $30.56(5.46)$ & $91.44(19.62)$ & $6.33(1.23)$ & $17.11(4.46)$ & $30.22(10.39)$ \\
$\quad \begin{array}{l}\text { Experimental } \\
\text { Control }\end{array}$ & $26.42(7.86)$ & $88.92(23.46)$ & $7.77(1.92)$ & $20.92(3.77)$ & $36.00(5.51)$ \\
\hline & $29.56(6.06)$ & $95.22(20.75)$ & $6.78(1.86)$ & $15.44(4.50)$ & $29.44(10.17)$ \\
\hline
\end{tabular}

Intervention Group

Control Group

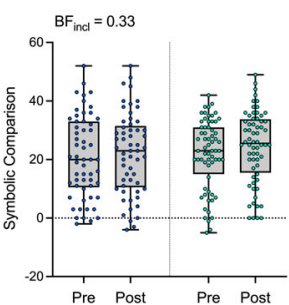

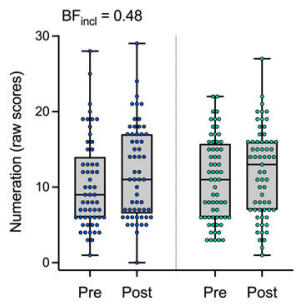
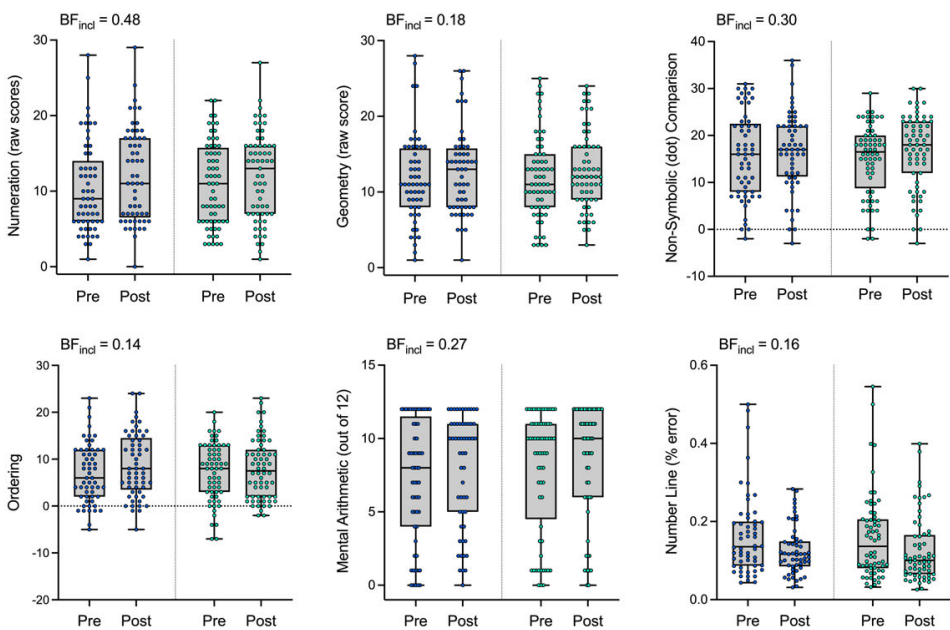

Figure 5. Comparison of pre-post-performance by students in the intervention and control groups (Year 2). 
Year 2 - student results

Preliminary analyses. Table 6 shows the mean scores and standard deviations by group at pre and post. No group differences were observed on any of the measures, suggesting that the groups were well-matched in age and performance.

Main analyses. A comparison of pre-post-gains can be seen in Table 6 and Figure 5. We found no evidence of pre-post-gains by the intervention group compared with the control group on any of the measures: Numeration(118), $\mathrm{BF}_{\text {incl }}=0.48$; Geometry(115), $\mathrm{BF}_{\text {incl }}=0.18$; Non-Symbolic Number Comparison $(117), \mathrm{BF}_{\text {incl }}=0.30 ;$ Symbolic Number Comparison(119), $\mathrm{BF}_{\text {incl }}=0.33$; Ordering(118), $\mathrm{BF}_{\text {incl }}=0.14$; Arithmetic(117), $\mathrm{BF}_{\text {incl }}=$ 0.27; Number Line $(\mathrm{PAE})(115), \mathrm{BF}_{\text {incl }}=0.16$; Visual-Spatial Working Memory - Forward Path Span(116), $\mathrm{BF}_{\text {incl }}=0.22$; Visual-Spatial Working Memory - Reverse Path Span(115), $\mathrm{BF}_{\text {incl }}=0.03$; Head-Toes-Knees-Shoulders (116), $\mathrm{BF}_{\text {incl }}=0.41 ;$ Raven's Matrices(117), $\mathrm{BF}_{\text {incl }}=0.39 ; 2 \mathrm{D}$ Mental Rotation(116), $\mathrm{BF}_{\text {incl }}=0.14 ;$ Visual-Spatial Reasoning(117), $\mathrm{BF}_{\text {incl }}=1.35$. Figure 5 shows all children's pre-post-scores by group and across all the mathematics measures (to view pre-post-scores by group for performance on the spatial and EF measures visit; https://osf.io/sp3nd/?view_only=f54807cfc99245ed8d1a8b256b 142187).

As a follow-up to the above analysis, we also carried out a series of within-group Bayesian repeated-measures ANOVAs. Because the intervention group had previously participated as the control group, we were able to test for differences in their growth across the two conditions (control vs. intervention; see Table 7). As outlined in our preregistration, we considered this analysis as a more robust and reliable measure of the effectiveness of the intervention. These analyses revealed three condition $\times$ time interactions with a Bayes factor greater than three. Children demonstrated greater gains on the Numeration test when part of the intervention condition compared to the control condition: Numeration $(46), \mathrm{BF}_{\text {incl }}=9.42$. Unexpectedly, children demonstrated greater gains on the Non-Symbolic Number Comparison task and HTKS task when part of the control group compared to the intervention group; Non-Symbolic Number Comparison (47), $\mathrm{BF}_{\text {incl }}=7.30$; Head-Toes-Knees-Shoulders $(45), \mathrm{BF}_{\text {incl }}=4.21$. On all of the remaining measures, there was no evidence of greater gains when children were members of the intervention compared to the control condition: Geometry(43), $\mathrm{BF}_{\text {incl }}=0.35$; Symbolic Number Comparison(47), $\mathrm{BF}_{\text {incl }}=0.78 ; \operatorname{Ordering}(47), \mathrm{BF}_{\text {incl }}=0.56$; $\operatorname{Arithmetic}(47)$, $\mathrm{BF}_{\text {incl }}=0.34$; Number Line $(\mathrm{PAE})(43), \mathrm{BF}_{\text {incl }}=0.70$; Visual-Spatial Working Memory Forward Path Span(43), $\mathrm{BF}_{\text {incl }}=0.75$; Visual-Spatial Working Memory - Reverse Path $\operatorname{Span}(43), \mathrm{BF}_{\text {incl }}=0.39$; Raven's Matrices(45), $\mathrm{BF}_{\text {incl }}=0.87 ; 2 \mathrm{D}$ Mental Rotation(45), $\mathrm{BF}_{\mathrm{incl}}=2.10$; Visual-Spatial Reasoning $(45), \mathrm{BF}_{\mathrm{incl}}=0.24$. Figure 6 shows children's gain scores across all four time points and under both conditions (intervention vs. control) for all the mathematics measures (see Table 7; to view gain scores by time and condition on the remaining spatial and EF measures visit: https://osf.io/fztk2/?view_only=f54807cfc 99245ed8d1a8b256b142187). 


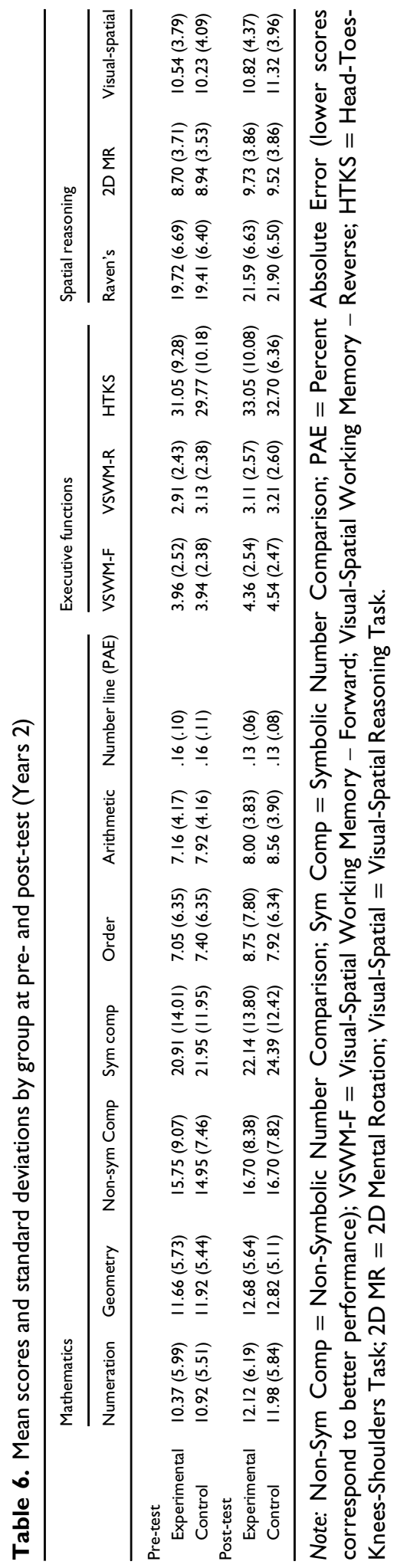




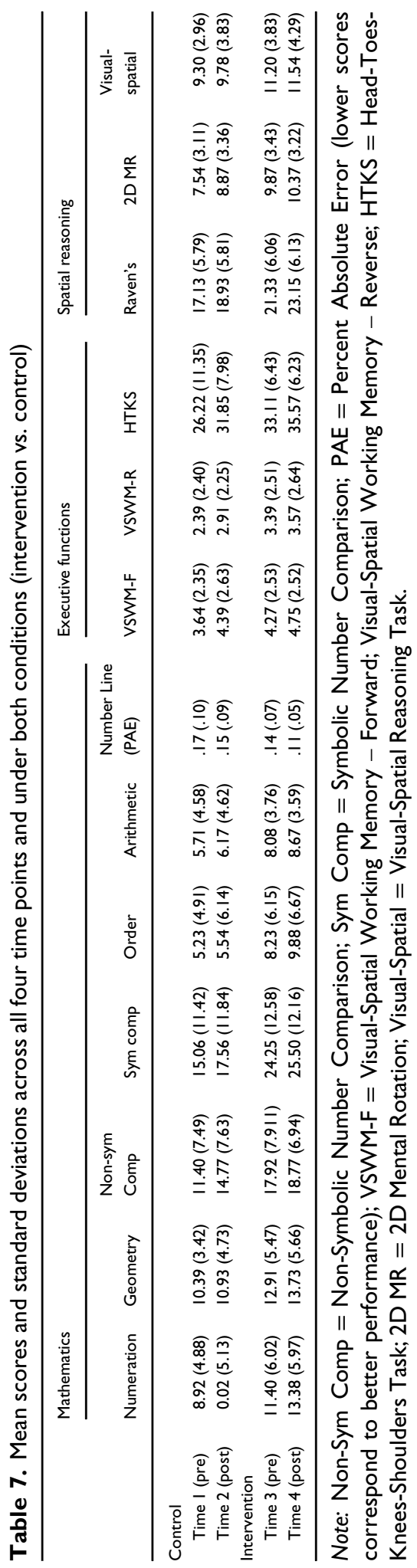



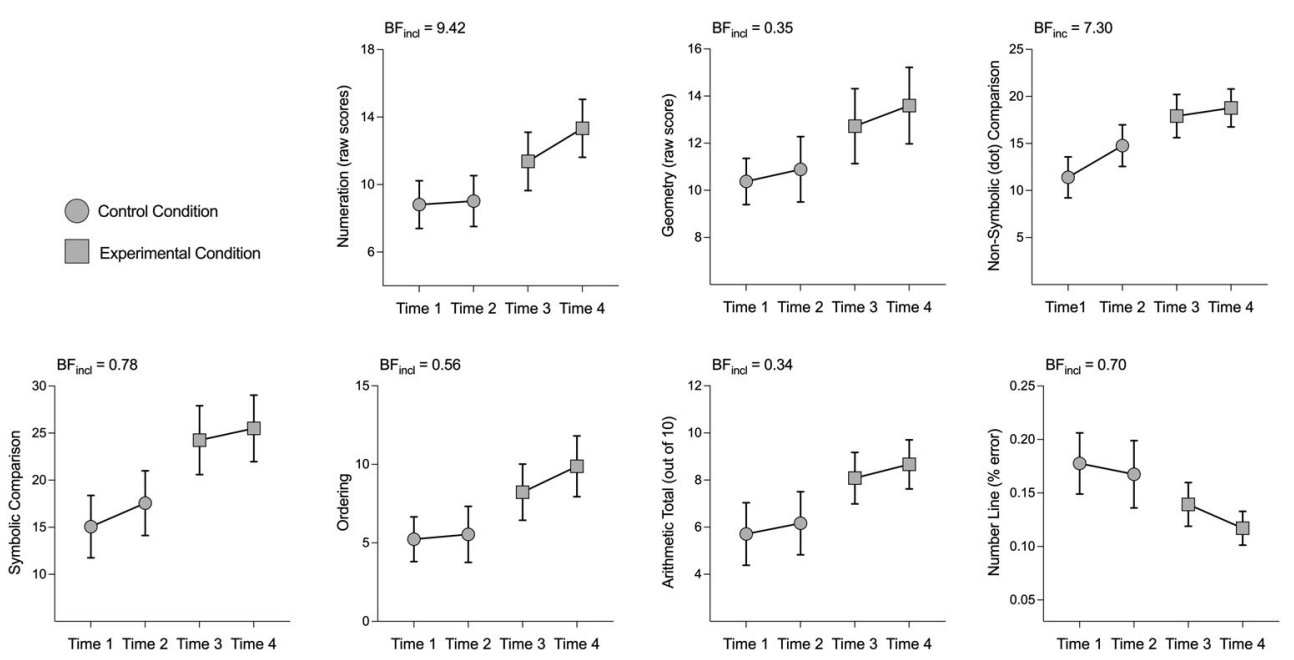

Figure 6. Within group change across multiple time points and under both conditions. Bars represent $95 \%$ confidence intervals around the mean.

\section{Summary of Year 2 results}

Relative to the control group, teachers in the intervention group demonstrated gains on the measure of self-perceived numerical cognition. Bayesian analyses indicated insufficient evidence to claim support for or against an effect on measures of numerical cognition knowledge and self-perceived general cognition knowledge. Thus, whether or not the intervention had an effect on these aspects of teacher knowledge remains ambiguous. Replicating the Year 1 results, there was support for the null on both the measure of math anxiety as well as comfort in the teaching and learning of mathematics. At the student level, there was no evidence of gains by the intervention group compared with the control group on any of the measures. However, the within-group analyses revealed a somewhat different picture, indicating greater improvements in children's numeration performance when they participated in the intervention compared to the control condition. Overall, the results of Year 2 indicate evidence of teacher gains in selfperceived knowledge of numerical cognition and partial evidence of student improvements in numeration.

\section{Implementation of teacher-led student intervention activities}

On average, the teachers in Year 1 engaged their students in the intervention activities for a total of nearly $12 \mathrm{hr}(M=11.80, S D=6.97$, range $=3.67-22.42 \mathrm{hr})$. In Year 2, teachers engaged their students in the intervention activities for an average of approximately $3 \mathrm{hr}$ $(M=3.37, S D=1.46$, range $=1.67-5.67 \mathrm{hr})$. A Bayesian independent $t$-test was conducted to assess whether and to what extent the two groups varied in the total time spent implementing the student intervention activities. Results revealed $B_{10}=6.74$, indicating a group difference in favour of the Year 1 teachers. Indeed, the Year 1 teachers engaged their students in the activities for approximately 3 and $1 / 2$ times longer than the Year 2 teachers. Also note that while all participating teachers in Year 1 returned their $\log$ sheets, one teacher in Year 2 failed to return theirs and another teacher's log sheet was incomplete and unusable. It is clear that teachers in Year 1 engaged their students in the intervention activities to a much greater extent than the teachers in Year 2. 
There was also a clear difference between groups in the number of items uploaded to each group's shared Google Drive. The Year 1 teachers uploaded 53 items compared with the 11 items uploaded by the Year 2 teachers.

\section{Discussion}

In this study, we designed, implemented, and tested the effects of a novel approach to teacher PD. The model was designed to better integrate research from the field of numerical cognition with the teaching and learning of early years mathematics. Through enriching teachers' awareness and understanding of research on children's numerical thinking, we hypothesized that teachers would be in a better position to assess student learning and plan and deliver mathematics instruction. To test this hypothesis, we studied the effects the PD intervention on teacher and student learning outcomes across two separate studies, over a 2-year period. Year 1 results indicated that relative to a control group, teachers who participated in the PD intervention demonstrated gains in their numerical cognition knowledge, self-perceived numerical cognition knowledge, and selfperceived general cognition knowledge. Compared to a control group, children in the intervention classrooms demonstrated gains in number line estimation, mental arithmetic (addition), and a comprehensive test of numeration. Together, these results provide evidence to suggest that the intervention was effective at increasing both teacher and student knowledge in the areas most specifically targeted throughout the intervention. However, our attempt to replicate these effects (Year 2) paints a somewhat different picture. In Year 2, teachers in the intervention group demonstrated greater improvements than the control group on a measure of self-perceived knowledge of numerical cognition. Thus, this result was consistent across both years. Unlike Year 1, however, we failed to replicate evidence of teacher gains in their actual content knowledge of numerical cognition. At the student level, there was no evidence that the intervention group outperformed the control group on any of the measures in Year 2. However, the withingroup analyses revealed greater improvements in children's numeration performance when they participated in the intervention compared with the control condition. This finding, coupled with the Year 1 results, provides some evidence that the intervention may have had a positive effect on children's numeration performance. As discussed in greater detail below, one reason we may have obtained mostly discrepant results between years of study may have been due to group differences in teacher uptake and implementation of the intervention. Overall, a careful weighing of the evidence across years of study suggests the current PD model is a viable approach to better integrate research and practice. What follows is a more detailed summary and interpretation of the effects of the PD, as well as explanations for the inconsistencies in findings between years of study. We conclude our discussion by considering limitations and next steps.

\section{Teacher results}

In both Year 1 and Year 2, teachers in the intervention reported higher levels of perceived numerical cognition knowledge compared with the control group. More specifically, at the end of the intervention, teachers who participated in the PD reported experiencing increased levels of knowledge on the following terms: numerical cognition, dyscalculia, mental number line, cardinality, and ordinality. As a follow-up to this measure, we also included a test of numerical cognition knowledge to assess the understanding of these and 
other terms in classroom-based contexts. To our surprise, improvements on this measure were present in Year 1 but not Year 2. Thus, although gains in self-perceived numerical cognition were consistent across years of study, improvement in actual numerical cognition knowledge was restricted to the Year 1 group.

If teachers' numerical cognition knowledge is more related to student learning than self-perceived knowledge, then we should expect to see greater evidence of student gains in Year 1 than Year 2. Indeed, there was stronger evidence for improvements in numerical reasoning by students in Year 1 compared with Year 2 . This finding is consistent with prior research, in which teachers' understanding of different facets of children's numerical thinking (e.g., arithmetic strategies) has been associated with gains in students' numerical thinking (e.g., see Carpenter et al., 1989; Fennema et al., 1996; Franke et al., 2001). However, upon closer reflection, it is clear that this trend in the current data needs to be interpreted with caution. Due to the small sample sizes and uneven distribution of students across grades, we were unable to directly address the question of whether teacher change was associated with student change and dissociable by group. Thus, statistically speaking, we were unable to state whether the gains in Year 1 were a result of greater gains in teachers' numerical cognition knowledge in Year 1 compared with Year 2.

The absence of intervention effects on teachers' math anxiety/comfort was far less ambiguous. Across both years of the study, on both a measure of teacher math anxiety and a separate measure of teacher comfort-level teaching and learning math, there was support in favour of the null: that is, there was enough evidence to suggest that the intervention did not have an effect in these areas. These results run counter to our original predictions. One reason for this finding may be due to measurement insensitivity. That is, the measures of math anxiety and math comfort level were fairly broad in scope and perhaps not specific enough to the mathematics targeted throughout our PD. Another possibility is that the PD made group members more aware of the complexities of teaching and learning mathematics, which, in turn, may have also heightened educators' awareness of their own math comfort and anxiety. The saying 'the more you know, the more you realize how much you don't know', offers an analogy. This interpretation offers a possible explanation for the overall slight increase in teachers' math anxiety.

Despite evidence to suggest our intervention was not effective at lowering teacher math anxiety, we still obtained some evidence of intervention-related improvements in student learning. Moving forward, it is clear that much more research is needed to uncover when, why, and how teachers' math anxiety is linked to student learning. Moreover, concerted efforts are needed to study the malleability of teacher math anxiety and the effect that reductions in math anxiety have on student learning.

\section{Student results}

The present intervention targeted both teachers and their students. While primary efforts were directed at intervening at the teacher level, our primary outcomes of interest were directed at the student level. To this aim, the implementation of the student intervention consisted of teacher-led activities targeting the three major foci of the teacher intervention: basic numerical relationships, number-space mappings, and arithmetic. Based on the success of the teacher intervention by Hawes et al. (2017), we provided teachers with a curated bank of numerical reasoning activities to draw from and implement in their own classrooms. These activities were aligned with the specific foci of the teacher PD, providing opportunities for teachers to make links between the PD and their practice. Furthermore, in line with design research practices, teachers were 
encouraged and given opportunities to adapt the activities based on their own professional judgement (Brown, 1992).

As noted above, the relative effectiveness of the teacher-led student intervention varied across Years 1 and 2. In Year 1, children in the experimental classrooms made larger improvements than children in the control classrooms on measures of mental arithmetic, number line estimation, and a comprehensive test of numeration. Critically, both groups of children made highly similar gains on measures of spatial and EF skills, which were not targeted during PD. Thus, the gains made by the experimental group were highly specific to activities designed and implemented as part of the PD. These results, coupled with the evidence of teacher change observed in Year 1, were in line with our original hypotheses, as well as the results of Hawes et al. (2017), and provided reasons to be confident in the current model of teacher PD. However, promising as these results appeared, it was important to us to see whether the results would replicate.

Despite employing the same methodologies as Year 1, only one of the teacher results replicated and none of the student-level results replicated. In fact, across all student-level measures, Bayesian analyses suggested more support for the null than the alternative hypothesis. However, slightly different results emerged when analysing the data with what we preregistered as a more stringent approach involving within-group comparisons. That is, we compared the same students' growth across the two different conditions, intervention versus control. These analyses indicated that students demonstrated larger gains in their numeration performance when they were part of the intervention group compared with the control group. These results are promising in so much as the numeration test is a psychometrically reliable and robust measure of children's overall numerical reasoning (Connolly, 2007).

\section{Explanations for the inconsistencies in findings across years}

There are many potential reasons for why we observed inconsistent findings between the 2 years of study. In discussing these reasons, we will limit ourselves to explanations that we see as most probable, based on the data as well as our own observations. First, as discussed above, the null results from the students in Year 2 may have been due to the null results obtained from the teacher measures of change in Year 2. Indeed, our Year 2 findings do not contradict our original hypotheses, but in some ways support it. That is, the success of the current intervention at the student level is dependent on the success of the intervention at the teacher level. If teachers show little evidence of change, it should be of little surprise that the students of these teachers also show little evidence of change. This leads to the critical question of why one group of teachers appeared to gain from the teacher intervention while another group did not.

A second possible reason for the discrepant findings between Year 1 and Year 2 has to do with group differences in uptake and implementation of the student-focused intervention activities. Rather than have teachers' carry out a fixed student intervention, teachers were encouraged to take the intervention activities and make them their own, adapting and extending them as they saw fit. We did this to foster a more collaborative and authentic learning environment (to disrupt perceived power relations between researcher and teacher) and as means to better integrate teacher agency, expertise, and feedback into the PD model. It was clear that the two groups responded very differently to this aspect of the PD. The Year 1 group regularly returned to each session with an eagerness and enthusiasm to share their experiences with implementation, including their modifications and the reasons for making such changes. The Year 2 group did not 
share this same level of participation, and sharing was kept to a minimum. These differences were also apparent in the teachers' activity logs. Compared to Year 2, teachers in Year 1 spent $3 \frac{1}{2}$ times the class time with their students in the intervention activities. For this reason alone, we may not have observed clear evidence of student gains in Year 2. Moving forward, it will be important to also examine factors related to the quality of teacher-led activity implementation and associations between quality of implementation and student learning. Further evidence that the two groups differed in the uptake and commitment to the project can be observed by comparing the shared Google Drives between groups. Recall that as part of the intervention teachers were encouraged to upload video/picture or paper-and-pencil examples of student reasoning, including student assessments and student work samples, as well as adapted versions of the student intervention activities. The Year 1 teachers uploaded 53 items compared with the 11 items uploaded by the Year 2 teachers. These data may reflect greater engagement of teachers in Year 1 compared with Year 2.

A third reason for the discrepant findings may be related to the involvement of the school principal. Indeed, prior research on what makes for effective teacher PD points to principal involvement as an important factor in increasing the likelihood of instructional improvement (Santagata, Kersting, Givvin, \& Stigler, 2011; Wanless, Patton, RimmKaufman, \& Deutsch, 2013; Wilson, 2013). In the present study, the school principal was visibly involved and a regular participant of the PD sessions in Year 1 (attending all 5 sessions) but not in Year 2 (attending no sessions). In line with the research literature cited above, the Year 1 principal not only participated, but also appeared to play a critical role as a leader in encouraging teacher uptake and commitment to the project. Prior to our first meeting, the principal had taken the time to explain to the group of participating teachers the purpose of the project. During the actual PD sessions, the principal asked questions, made connections between research and practice, and perhaps most importantly, demonstrated a keen interest in learning from the project. In between sessions, the principal visited the teachers' classrooms to observe the implementation of the student activities and shared her observations of student learning in our subsequent meetings together. Taken together, we have some evidence to suggest that the school principal plays an important role in liaising teacher-researcher collaborations.

A fourth and final reason for the difference in success between years of study may have been related to the degree of (mis)alignment between researcher and teacher goals. The overall goal of this project was to improve children's numerical thinking. However, the extent to which this was a priority among the two groups of teachers appeared to vary. This was clear throughout the PD, but was especially apparent during our concluding focus group interviews, held during the last $45 \mathrm{~min}$ of the final session. Teachers were asked to reflect on and share their thoughts about the PD process. In Year 1, not only was there widespread support for the approach to teacher PD but there was also clear alignment between teachers' perceptions of the PD and our researcher-designed rationale and purpose behind each component of the PD. In other words, teachers in Year 1 were easily able to identify and appreciate the purpose of the PD and its various components. For example, in the following quote by a Year 1 2nd-grade teacher, we see evidence of appreciation for this approach to PD, but also some evidence of teacher-researcher goal alignment:

I think this is the best PD I've ever had - like ever - and it's obvious I've been doing this for a while. It was more of an in-depth understanding of how really children learn math and mathematical concepts, and things like that. And then what I did personally, I took that and 
looked at the curriculum and it really helped me blend the two together. I absolutely didn't discount the curriculum because that's where our direction is, and I really incorporated a lot of what you guys offered to us. . . and I just think it's a really good way to offer PD for teachers. It was wonderful, I really enjoyed it (Educator, Year 1; 25 years of experience).

This teacher's mention of taking what she has learned about how children learn mathematics and applying it to the mathematics curriculum speaks to one of the ultimate goals of this approach to PD. In line with the principles of CGI (e.g., see Carpenter, 1989, 2014; Fennema et al., 1996), we aimed to equip teachers with a better understanding of children's numerical reasoning and in turn a better 'mental model' of the learner (Willingham, 2017). In this way, teacher learning is not bound to the delivery of specific lessons/activities, but has the potential to be applied across a number of contexts, including various aspects of the curriculum. Other teachers also referred to the PD process as an effective means to bridge research and practice, making explicit mention of the importance of going beyond giving 'lip service' to research and instead highlighted the need go one step further, that is, use research to inform the design and actual implementation of student-focused activities. Moreover, it is clear from the quotes below that teachers appreciated working with their students in an effort to bridge research and practice:

I liked how the research translated into activities. So, if the research says children need to be able to do these things, then let's build some activities that will actually get students to do these things. But I thought that was really powerful. That's kind of that marriage of research with professional practice that seems to not happen a lot. (Educator, Year 1)

The fact that we would hear it [research] and we went back and did it. Because you go to an outside PD and you sit there all day, and they tell you this and this and this, and they give you the research behind it. . . and if you're skeptical at all, you're going yeah right. And you come back to class and you don't necessarily do it because you are skeptical about it, but here, we did it, we tried it. We went, just like [teacher] said, 'woah, yeah, I would have never thought to do that and look what happened. (Educator, Year 1)

Well, I guess I might be interpreting research a little bit bigger than this, but I think when you bring those students in [to the shared meeting space in the library] and those teachers are working with their own students and making those observations that are so powerful saying 'I never thought about that, I forgot to think about that.' I think our teachers become researchers and that becomes very powerful. . I think that makes a huge difference. This part of the PD where you're bringing your students in is the most powerful, I think. (Educator, Year 1)

Collectively, these quotes speak to what William James referred as the necessity of intermediary actions in order to bridge the research-to-practice gap (James, 1899). These teachers were able to identify the purpose of conducting one-to-one assessments with students and piloting activities with students as a whole group. They saw these components of the PD as effective mechanisms in making the translation from research to practice.

This same level of participation and ability to provide mechanistic accounts of the various components of the PD was not as apparent in Year 2. Although teachers spoke of the PD in positive terms, there was far less indication that teachers, both as individuals and as a collective, identified with the purpose of the PD. There was little talk about the specific components of the PD model and at no point any explicit mention of how this 
model may better afford the application of research to practice. Instead, much of the conversation was centred around topics relevant to student learning, but tangential to the actual PD experience. For example, the majority of our conversation centred around questions and concerns about their students' home lives and 'emotional availability to learn'.

I would really like to get some more insight, I guess, understanding of children coming to school that aren't prepared to learn, that aren't able to learn. (Educator, Year 2)

Because they're [the students] kind of in that flight response all the time. So, they're not available to learn cause they're there, right? (Educator, Year 2)

The amount of time spent discussing issues related to their students' home lives is potentially indicative of a lack of teacher-researcher goal alignment. Simply put, the teachers in Year 2 may not have been engaged with the PD we had to offer because they saw the need for PD of a different sort; for example, PD that places greater emphasis on understanding the emotional and behavioural well-being of their students. However, it should also be mentioned that the Year 1 teachers also identified students' behavioural and emotional challenges as key obstacles in their ability to carry out effective instruction. It is unclear to us why educators at one school were differentially able to engage in this PD topic more than the other. We must also be careful not to assume the needs of both schools were the same, despite serving students of the same neighbourhood and their almost identical performance on both cognitive and academic measures of achievement. It is possible that the particular cohort of students in the Year 2 school presented a unique set of problems; more severe than what was experienced in the Year 1 school. In returning to the idea of teacher-researcher goal alignment, it is plausible that the goals of our intervention were at odds with the school's identified need to prioritize the emotional and behavioural well-being of their students. In future iterations of the model, we aim to further investigate the potential moderating influence that teacher-researcher goal alignment has on the implementation and overall success of the intervention.

\section{Limitations and next steps}

There are several limitations of this study worth pointing out. First, the teacher sample sizes were small. This prevented us from directly assessing how teacher change related to student change as a function of the intervention. Moving forward, it will be important to demonstrate whether, to what extent, and what particular aspects of teacher learning are related to student growth. For example, our findings provide some hints that teachers' numerical cognition knowledge may be more strongly related to students' numerical thinking than teachers' self-perceived numerical cognition knowledge. However, larger sample sizes, at the teacher level, are needed to directly address this line of inquiry. Moreover, increasing the number of participating schools is also an important future direction. It seems likely that the effects of the PD not only operate at the individual level, but school level as well. For example, school level variables, such as school climate and team cohesiveness, may help to further explain differences in the uptake and effectives of the PD model, differences that are not accounted for by looking at individual teachers alone.

Moving forward, it will be important to more thoroughly examine the specific ways in which the intervention may have influenced teachers' assessment and instructional 
practices. For example, although anecdotal evidence from Year 1 suggests that teachers were better able to apply research-to-practice, it remains unclear how exactly this manifested itself in practice. We have hypothesized that a better understanding of research on children's thinking provides teachers with a better basis on which to observe (assess) and extend children's thinking during instruction. For example, one must know what cardinality is in order to look for it in student reasoning, identify it as an area of strength/concern, and then use these observations to plan for appropriate instruction. Given that teachers are likely to differ on how they perceive and use research to inform assessment and instruction, it is critical to capture these differences and ultimately relate them to student thinking. Fennema et al. (1996), for example, were able to show that their approach to teacher PD (i.e., CGI) was related to increases in teachers' attention to and instructional focus on mathematical problem solving. This change, in turn, was related to student gains in problem solving. It is this sort of detail that will be important to document in future research of the current model.

Lastly, it is worth asking whether the PD model itself may be a limitation in the pursuit of establishing an effective intervention. In other words, should we consider abandoning the model altogether, making changes to the model, or keep the model entirely intact? At this point, we side with keeping the model intact and instead urge the need for more research. Although we did not obtain unambiguous support for the model, we did see evidence of teacher and student gains in Year 1. More importantly, it seems that the gains observed in Year 1 and the mostly absent gains in Year 2 could be attributed to poor uptake and implementation of the PD. However, it has also become clear that this potential rests on a variety of factors that, at the moment, remain poorly understood. As others have shown, it may not be enough to build a model of teacher PD based on established features of effective PD (Hill, Corey, \& Jacob, 2018). Indeed, even when teacher PD models do incorporate effective features of $\mathrm{PD}$, including sustained focus on student's mathematical thinking, studies of these models yield mixed results (Hill et al., 2018; Jacob, Hill, \& Corey, 2017). By including two studies of the same approach to teacher PD, but with differing results across the two contexts, we were able to further examine why this might be. While we have suggested these differences reside in uptake and implementation, future efforts are needed to follow-up on these possibilities and examine their influence with finer grained analyses and measurement.

\section{Conclusion}

This study provides new insights into an old problem: How to address the research-topractice gap? We demonstrate 'proof of concept' for the design and implementation of a 5day teacher PD model that aims to better integrate numerical cognition research and the teaching of early years mathematics. Our approach is interdisciplinary in design, built to foster improved communication and understanding of children's learning among both researchers and practitioners alike. For this reason, we see the model as one not limited to bridging numerical cognition research and practice, but as one that has the potential to be applied to other research-practice gaps (e.g., literacy). Although the current findings provide some indication that the model is effective at bringing about change at both the level of teacher and student, the inconsistent findings between Years 1 and 2 make it clear that more research is needed. More specifically, in contrasting the results from Years 1 and 2 , it may not be strictly a question of whether the model is effective but also a question as to when and under what conditions the model is effective. We obtained evidence to suggest widespread buy-in and uptake in Year 1, and less evidence of this in the Year 2 group. This 
is but one plausible reason for the discrepancies in results. Moving forward, it will be important to more systematically examine why the same approach and model of teacher PD might be taken up differently in different contexts.

\section{Conflicts of interest}

All authors declare no conflict of interest.

\section{Acknowledgements}

Our deepest gratitude goes to the participating teachers. This project would not have been possible without you and the many contributions you made to the project. It was a joy to learn from you and your students. We must also thank the early and ongoing support, financial and otherwise, of the Thames Valley District School Board, with special thanks to Scott Armstrong, Riley Culhane, and Kevin Auckland. A huge thank you to Lien Peters and the insights and expertise she offered on the 'mathematical brain.' Lastly, we are grateful for the funding and research opportunities made possible through the following organizations: A Jacobs Advanced Research Fellowship awarded to DA, Brain Canada and NeuroDevNet Developmental Neuroscience Training award to R.M, and Social Sciences and Humanities Research Council of Canada (SSHRC) Doctoral Fellowship to ZH.

\section{Author contribution}

Zachary Hawes, (Conceptualization; Data curation; Formal analysis; Funding acquisition; Investigation; Methodology; Visualization; Writing - original draft) Rebecca Merkley, PhD (Investigation; Writing - review \& editing) Christine L. Stager, $\mathrm{PhD}$ (Funding acquisition; Methodology; Writing - review \& editing) Daniel Ansari, PhD (Conceptualization; Funding acquisition; Investigation; Methodology; Supervision; Writing - review \& editing).

\section{Data availability statement}

Data are available upon request.

\section{References}

Alexander, L., \& Martray, C. (1989). The development of an abbreviated version of the Mathematics Anxiety Rating Scale. Measurement and Evaluation in Counseling and Development, 22, $143-$ 150. https://doi.org/10.1080/07481756.1989.12022923

Asquith, P., Stephens, A. C., Knuth, E. J., \& Alibali, M. W. (2007). Middle school mathematics teachers' knowledge of students' understanding of core algebraic concepts: Equal sign and variable. Mathematical Thinking and Learning, 9, 249-272. https://doi.org/10.1080/ 10986060701360910

Ball, D. L., Thames, M. H., \& Phelps, G. (2008). Content knowledge for teaching: What makes it special? Journal of Teacher Education, 59, 389-407. https://doi.org/10.1177/ 0022487108324554

Baroody, A. J., \& Ginsburg, H. P. (1983). The effects of instruction on children's understanding of the "equals" sign. The Elementary School Journal, 84, 199-212. https://doi.org/10.1086/461356 
Beilock, S. L., Gunderson, E. A., Ramirez, G., \& Levine, S. C. (2010). Female teachers' math anxiety affects girls' math achievement. Proceedings of the National Academy of Sciences, 107, 18601863. https://doi.org/10.1073/pnas.0910967107

Brown, A. L. (1992). Design experiments: Theoretical and methodological challenges in creating complex interventions in classroom settings. The Journal of the Learning Sciences, 2, 141-178. https://doi.org/10.1207/s15327809j1s0202_2

Bruce, C. D., Flynn, T. C., \& Bennett, S. (2016). A focus on exploratory tasks in lesson study: The Canadian 'Math for Young Children' project. ZDM-The International Journal on Mathematics, 48(4), 541-554.

Bruce, C. D., \& Hawes, Z. (2015). The role of 2D and 3D mental rotation in mathematics for young children: What is it? Why does it matter? And what can we do about it? ZDM-The International Journal on Matbematics, 47(3), 331-343.

Byrd, C. E., McNeil, N. M., Chesney, D. L., \& Matthews, P. G. (2015). A specific misconception of the equal sign acts as a barrier to children's learning of early algebra. Learning and Individual Differences, 38, 61-67. https://doi.org/10.1016/j.lindif.2015.01.001

Carpenter, T., Fennema, E., Franke, M., Levi, L., \& Empson, S. (2014). Children's mathematics, second edition: Cognitively guided instruction. Portsmouth, NH: Heinemann.

Carpenter, T. P., Fennema, E., Peterson, P. L., Chiang, C. P., \& Loef, M. (1989). Using knowledge of children's mathematics thinking in classroom teaching: An experimental study. American Educational Research Journal, 26, 499-531. https://doi.org/10.3102/00028312026004499

Clarke, D., Clarke, B., \& Roche, A. (2011). Building teachers' expertise in understanding, assessing and developing children's mathematical thinking: The power of task-based, one-to-one assessment interviews. Zdm-the International Journal on Mathematics Education, 43 (6-7), 901-913. https://doi.org/10.1007/s11858-011-0345-2

Collins, A. (1992). Toward a design science of education. In E. Scanlon, \& T. O'Shea (Eds.), New directions in educational technology. NATO ASI Series (Series F: Computer and Systems Sciences), Vol. 96. Berlin, Germany: Springer.

Collins, A., Joseph, D., \& Bielaczyc, K. (2004). Design research: Theoretical and methodological issues. The Journal of the Learning Sciences, 13(1), 15-42. https://doi.org/10.1207/ s15327809j1s1301_2

Connolly, A. J. (2007). KeyMath diagnostic assessment (3rd ed.). Minneapolis, MN: Pearson.

Dubinsky, J. M., Roehrig, G., \& Varma, S. (2013). Infusing neuroscience into teacher professional development. Educational Researcher, 42, 317-329. https://doi.org/10.3102/ 0013189 X13499403

Duncan, G. J., Dowsett, C. J., Claessens, A., Magnuson, K., Huston, A. C., Klebanov, P., , . Japel, C. (2007). School readiness and later achievement. Developmental Psychology, 43, 1428-1446. https://doi.org/10.1037/0012-1649.43.6.1428

Falkner, K., Levi, L., \& Carpenter, T. (1999). Children's understanding of equality: A foundation for algebra. Teaching Children Mathematics, 6, 232-236. https://doi.org/10.5951/TCM.6.4.0232.

Fennema, E., Carpenter, T. P., Franke, M. L., Levi, L., Jacobs, V. R., \& Empson, S. B. (1996). A longitudinal study of learning to use children's thinking in mathematics instruction. Journal for Research in Mathematics Education, 27, 403-434. https://doi.org/10.2307/749875

Franke, M. L., Carpenter, T., Fennema, E., Ansell, E., \& Behrend, J. (1998). Understanding teachers' self-sustaining, generative change in the context of professional development. Teaching and Teacher Education, 14(1), 67-80. https://doi.org/10.1016/S0742-051X(97)00061-9

Franke, M. L., Carpenter, T. P., Levi, L., \& Fennema, E. (2001). Capturing teachers' generative change: A follow-up study of professional development in mathematics. American Educational Research Journal, 38, 653-689. https://doi.org/10.3102/00028312038003653

Ginsburg, H. P. (1997). Entering the child's mind: The clinical interview in psychological research and practice. New York, NY: Cambridge University Press.

Goffin, C., Sokolowski, H. M., Matejko, A. A., Bugden, S., Lyons, I. M., \& Ansari, D. (2018). Assessing knowledge translation in the field of mind, brain and education in pre-service teachers. 
International Mind, Brain, and Education Society Conference. Los Angeles: Mind, Brain, and Education Society.

Hawes, Z., Moss, J., Caswell, B., Naqvi, S., \& MacKinnon, S. (2017). Enhancing children's spatial and numerical skills through a dynamic spatial approach to early geometry instruction: Effects of a 32-week intervention. Cognition and Instruction, 35(3), 236-264.

Hill, H. C., Corey, D. L., \& Jacob, R. T. (2018). Dividing by zero: Exploring null results in a mathematics professional development program. Teachers College Record, 120 , n6.

Jacob, R., Hill, H., \& Corey, D. (2017). The impact of a professional development program on teachers' mathematical knowledge for teaching, instruction, and student achievement. Journal of Research on Educational Effectiveness, 10, 379-407. https://doi.org/10.1080/19345747. 2016.1273411

James, W. (1899/2001). Talks to teachers on psychology and to students on some of life's ideals. New York, NY: Dover Publications.

Jarosz, A. F., \& Wiley, J. (2014). What are the odds? A practical guide to computing and reporting Bayes factors. The Journal of Problem Solving, 7(1), 2-9. https://doi.org/10.7771/1932-6246. 1167

Kang, S. H. (2016). Spaced repetition promotes efficient and effective learning: Policy implications for instruction. Policy Insights from the Behavioral and Brain Sciences, 3, 12-19. https://doi. org/10.1177/2372732215624708

Laski, E. V., \& Siegler, R. S. (2007). Is 27 a big number? Correlational and causal connections among numerical categorization, number line estimation, and numerical magnitude comparison. Child Development, 78, 1723-1743. https://doi.org/10.1111/j.1467-8624.2007.01087.x

Lyons, I. M., Bugden, S., Zheng, S., De Jesus, S., \& Ansari, D. (2018). Symbolic number skills predict growth in no symbolic number skills in kindergarteners. Developmental Psychology, 54(3), $440-457$.

Lyons, I. M., Hutchison, J. E., Bugden, S., Goffin, C., \& Ansari, D. (2018). Kindergarteners reliability mis-classify ordered sequences of non-adjacent numbers. Paper presented at the Mathematical Cognition and Learning Society conference. Oxford, UK: Oxford University.

Maloney, E. A., \& Beilock, S. L. (2012). Math anxiety: Who has it, why it develops, and how to guard against it. Trends in Cognitive Sciences, 16, 404-406. https://doi.org/10.1016/j.tics.2012.06. 008

Mast, J. V., \& Ginsburg, H. P. (2010). Child study/lesson study: Developing minds to understand and teach children. In N. Lyons (Ed.), Handbook of reflection and reflective inquiry: Mapping a way of knowing for professional reflective inquiry (pp. 257-271). New York, NY: Springer Publishing Co.

Matthews, P. G., \& Fuchs, L. S. (2020). Keys to the gate? Equal sign knowledge at second grade predicts fourth-grade algebra competence. Child Development, 91(1), e14-e28. https://doi. org/10.1111/cdev.13144

McNeil, N. M., \& Alibali, M. W. (2005). Why won't you change your mind? Knowledge of operational patterns hinders learning and performance on equations. Child Development, 76, 883-899. https://doi.org/10.1111/j.1467-8624.2005.00884.x

McNeil, N. M., Fyfe, E. R., \& Dunwiddie, A. E. (2015). Arithmetic practice can be modified to promote understanding of mathematical equivalence. Journal of Educational Psychology, 107, 423436. https://doi.org/10.1037/a0037687

McNeil, N. M., Hornburg, C. B., Brletic-Shipley, H., \& Matthews, J. M. (2019). Improving children's understanding of mathematical equivalence via an intervention that goes beyond nontraditional arithmetic practice. Journal of Educational Psychology, 111, 1023-1044. https://doi.org/10. 1037/edu0000337

Moss, J., Bruce, C. D., Caswell, B., Flynn, T., \& Hawes, Z. (2016). Taking shape: Classroom activities to improve young children's geometric and spatial thinking. Toronto, ON: Pearson.

Moss, J., Hawes, Z., Naqvi, S., \& Caswell, B. (2015). Adapting Japanese Lesson Study to enhance the teaching and learning of geometry and spatial reasoning in early years classrooms: A case study. ZDM - The International Journal on Mathematics Education, 47(3), 377-390. 
Nathan, M. J., \& Sawyer, K. (2014). Foundations of learning sciences. In K. Sawyer (Ed.), The Cambridge handbook of the learning sciences (2nd ed.; pp. 21-43). Cambridge, UK: Cambridge University Press.

Okamoto, Y., \& Case, R. (1996). Exploring the microstructure of children's central conceptual structures in the domain of number. Monographs of the Society for Research in Child Development, 61, 27-58. https://doi.org/10.2307/1166077

Powell, S. R., Berry, K. A., Fall, A. M., Roberts, G., Fuchs, L. S., \& Barnes, M. A. (2020). Alternative paths to improved word-problem performance: An advantage for embedding prealgebraic reasoning instruction within word-problem intervention. Journal of Educational Psychology. https://doi.org/10.1037/edu0000513

Rohrer, D. (2015). Student instruction should be distributed over long time periods. Educational Psychology Review, 27, 635-643. https://doi.org/10.1007/s10648-015-9332-4

Rouder, J. N., Morey, R. D., Verhagen, J., Swagman, A. R., \& Wagenmakers, E. J. (2017). Bayesian analysis of factorial designs. Psychological Methods, 22, 304-321. https://doi.org/10.1037/me t0000057

Santagata, R., Kersting, N., Givvin, K. B., \& Stigler, J. W. (2011). Problem implementation as alever for change: An experimental study of the effects of a professional development program on students' mathematics learning. Journal of Research on Educational Effectiveness, 4(1), 1-24. https://doi.org/10.1080/19345747.2010.498562

Schaeffer, M. W., Rozek, C. S., Maloney, E. A., Berkowitz, T., Levine, S. C., \& Beilock, S. L. (2020). Elementary school teachers' math anxiety and students' math learning: A large-scale replication. Developmental Science, e13080. https://doi.org/10.1111/desc.13080

Schönbrodt, F. D., Wagenmakers, E. J., Zehetleitner, M., \& Perugini, M. (2017). Sequential hypothesis testing with Bayes factors: Efficiently testing mean differences. Psychological Methods, 22, 322-339. https://doi.org/10.1037/met0000061

Simon, H. A. (1969). The sciences of the artificial. Cambridge, MA: MIT Press.

Wanless, S. B., Patton, C. L., Rimm-Kaufman, S. E., \& Deutsch, N. L. (2013). Setting-level influences on implementation of the Responsive Classroom approach. Prevention Science, 14(1), 40-51. https://doi.org/10.1007/s11121-012-0294-1

Willingham, D. T. (2017). A mental model of the learner: Teaching the basic science of educational psychology to future teachers. Mind, Brain, and Education, 11, 166-175. https://doi.org/10. $1111 /$ mbe. 12155

Wilson, S. M. (2013). Professional development for science teachers. Science, 340, 310-313. https:// doi.org/10.1126/science.1230725

Received 2 I September 2020; revised version received 22 March 202 I 